\title{
On the relation of boredom and sadistic aggression
}

\author{
Stefan Pfattheicher ${ }^{1}$, Ljiljana B. Lazarević ${ }^{2}$, Erin C. Westgate $^{3}, \&$ Simon Schindler $^{4}$ \\ ${ }^{1}$ Aarhus University, Denmark; ${ }^{2}$ University of Belgrade, Serbia; \\ ${ }^{3}$ University of Florida, United States; ${ }^{4}$ University of Kassel, Germany
}

In press at Journal of Personality and Social Psychology

(C) 2020, American Psychological Association. This paper is not the copy of record and may not exactly replicate the final, authoritative version of the article.

Corresponding author:

Stefan Pfattheicher

Aarhus University

Department of Psychology and Behavioral Sciences

8000 Aarhus C, Denmark

sp@psy.au.dk 


\begin{abstract}
What gives rise to sadism? While sadistic behavior (i.e., harming others for pleasure) is welldocumented, past empirical research is nearly silent regarding the psychological factors behind it. We help close this gap by suggesting that boredom plays a crucial role in the emergence of sadistic tendencies. Across nine diverse studies, we provide correlational and experimental evidence for a link between boredom and sadism. We demonstrate that sadistic tendencies are more pronounced among people who report chronic proneness to boredom in everyday life (Studies 1A-1F, $N=1780$ ). We then document that this relationship generalizes across a variety of important societal contexts, including online trolling; sadism in the military; sadistic behavior among parents; and sadistic fantasies (Studies 2-5, N=1740). Finally, we manipulate boredom experimentally and show that inducing boredom increases sadistic behavior (i.e., killing worms; destroying other participants' pay; Studies 6-9, $N=4097)$. However, alternatives matter: When several behavioral alternatives are available, boredom only motivates sadistic behavior among individuals with high dispositional sadism (Study 7). Conversely, when there is no alternative, boredom increases sadistic behavior across the board, even among individuals low in dispositional sadism (Studies 8\&9). We further show that excitement and novelty seeking mediate the effects of boredom, and that boredom not only promotes sadistic (proactive) aggression, but reactive aggression as well (Study 9). Overall, the present work contributes to a better understanding of sadism and highlights the destructive potential of boredom. We discuss implications for basic research on sadism and boredom, as well as applied implications for society at large.
\end{abstract}

Keywords: aggression; boredom; destructiveness; harm; sadism 


\section{Introduction}

The beauty of human goodness is clouded when we turn our focus to humans' inclination

for destructiveness. The present research contributes to our understanding of one particular type of destructiveness: sadism. We argue that boredom plays a crucial but overlooked role in the emergence of sadistic tendencies (i.e., harming others for pleasure).

In pursuing this idea, the present work has three central aims. The first is to better understand the conditions that motivate sadistic tendencies. Past research in social and personality psychology has focused on individual differences in sadism and how these relate to other destructive tendencies (e.g., playing violent video games; Greitemeyer, 2015). However, there is a substantial gap in the literature regarding the question of which (situational) conditions motivate sadistic tendencies. In fact, we know little about when sadistic tendencies actually emerge. In proposing that boredom plays a crucial motivational role in this process, we aim to fill this important gap in our understanding of the emergence of sadism.

Second, we complement the literature on boredom, which has struggled with the question of whether boredom is beneficial or harmful, particularly in interpersonal contexts. To date, boredom has been associated with a wide array of intra-personal tendencies, many maladaptive, such as anxiety, depression (e.g., LePera, 2011), compulsive gambling (Mercer \& Eastwood, 2010), self-harm (Chapman \& Dixon-Gordon, 2007), and substance use (Lee et al., 2007) but also a few positive tendencies (e.g., creativity, doodling, and mind wandering that facilitates creative problem solving; Andrade, 2010; Baird et al., 2012; Harris, 2000). However, we still know relatively little about the interpersonal consequences of boredom (cf. van Tilburg \& Igou, 2016) and nothing at all about the potential negative inter-personal consequences of boredom. In fact, to our knowledge, this is the first work to examine (and find) that boredom can cause harmful behavior towards other individuals in the form of sadistic aggression. As such, the present 
contribution adds an important piece of knowledge to the literature on boredom and draws a more nuanced picture by taking into account the destructive potential of boredom.

Our third aim is to approach the question of boredom and sadism from a societal perspective in considering the extent to which boredom's effect on sadism generalizes across impactful real-world contexts. Specifically, we aimed at documenting the many important applied contexts in which boredom can foster sadism. To this end, we tested the hypothesis that boredom motivates sadism in a variety of highly relevant societal contexts: We tested the prediction that boredom proneness in life motivates harassing others for fun on the internet; in a sample of U.S. military servicemen and women, we examined the relationship between boredom during military service and harming others for fun; we studied whether parents' boredom during child care is associated with sadistic actions towards the child; and, we tested whether boredom proneness predicts sadistic fantasizing, such as fantasizing about shooting someone for fun. Below, we outline the current state of research on sadism and boredom. Subsequently, we present a framework for why boredom motivates sadism.

\section{A motivational perspective on sadism}

The very essence of sadism is deriving pleasure from inflicting harm and suffering upon another individual (Dietz et al., 1990; Međedović, 2017; O’Meara et al., 2011). Pleasure in the context of sadism is typically applied broadly to refer to general positive affect, including specific emotions such as joy and excitement (Buckels, 2018; Chester, 2017). Since sadism involves inflicting harm on another individual (and deriving pleasure from it), sadism can be considered a type of aggression, defined as "any form of behavior directed toward the goal of harming or injuring another living being who is motivated to avoid such treatment" (p.7, Baron \& Richardson,1994). Thus, sadism is one manifestation of aggression, which places the present contribution within the wider context of research on the causes and consequences of aggression, broadly construed. 
In defining sadism, one must of course point to its similarities (and differences) with other “dark" tendencies, particularly the Dark Triad of psychopathy, Machiavellianism, and narcissism (Paulhus, 2014). Sadism shares with these other dark tendencies a disregard for other individuals' preferences (Bertl et al., 2017; Moshagen et al., 2018; Paulhus, 2014), and some argue that such dark tendencies cluster together under the trait of "antagonism” (Lynam \& Miller, 2019; Miller et al., 2019). Consistent with this, past research finds individual differences in sadism to be positively correlated with a variety of other dark traits (Moshagen et al., 2018). What makes sadism conceptually unique, however, is its tendency to derive pleasure from the suffering of others (Anderson \& Marcus, 2019; Chester et al., 2019; Johnson et al., 2019; Paulhus, 2014). This aspect of "pleasure via inflicted suffering" is not an essential feature in any of the other dark traits and thus constitutes sadism's unique defining feature. That is, someone may have a psychopathic disorder, or may be Machiavellian or narcissistic, without choosing to seek pleasure by causing suffering to others. Supporting its specificity, sadism predicts unique variance in its correlates even after controlling for other dark traits (e.g., Johnson et al., 2019; Moshagen et al., 2018).

Sadism emerges in both clinical and subclinical contexts (Chabrol et al., 2009). Past work has shown that sadism plays a unique motivational role (i.e., beyond other "dark" tendencies) in killing bugs (Buckels et al., 2013); harming an unknown person—even at personal cost (Buckels et al., 2013; Pfattheicher et al., 2017); online "trolling," or the practice of destructive behavior towards others on the internet (Buckels et al., 2014); punishing cooperative interaction partners (Pfattheicher \& Schindler, 2015; Pfattheicher et al., 2017); sexual aggression towards women (Russell \& King, 2016); vandalism (Pfattheicher, Keller, \& Knezevic, 2019); bullying (van Geel et al., 2017); and, playing violent video games (Greitemeyer, 2015; Greitemeyer \& Sagioglou, 2017; Greitemeyer et al., 2019). These findings suggest that sadism motivates behavior across a myriad of different contexts. 
Despite this large body of work, however, there is little research on when sadistic tendencies actually emerge or are promoted. Previous research has shown that individuals with a high predisposition to sadism are particularly likely to engage in sadistic behavior when forced to behave impulsively (Pfattheicher et al., 2017), or when existentially threatened via mortality salience (Pfattheicher \& Schindler, 2015). Chester and DeWall (2017) found increased sadistic tendencies (both in sadistic affect and behavior) after social rejection or provocation (see also Chester et al., 2019). In other words, sadism is more common under certain kinds of threat (e.g., social rejection, existential threat) and when people act impulsively. But this surprisingly sparse evidence speaks to the point that research on the conditions under which sadistic tendencies emerge is still in its infancy. Our present contribution addresses this gap and proposes that boredom is one such facilitator of sadistic behavior.

\section{Boredom as an aversive motivational state}

Boredom is an aversive state signaling that there is little value in persisting with one's current task - and motivates people to take action to feel better. In the words of Eastwood and colleagues (2012), boredom is "the aversive experience of wanting, but being unable, to engage in satisfying activity" (p.482), experienced when individuals are unable or unwilling to engage their attention or find meaning in what they are doing (Westgate \& Wilson, 2018). While boredom comes in many variants, prototypical instances of boredom involve mixed attentional and meaning deficits, characterized by negative valence, difficulty concentrating, heightened (or lowered) arousal, and an altered sense of time (Chin et al., 2017; Eastwood et al., 2012; Troutwine \& O’Neal, 1981; van Tilburg \& Igou, 2012; van Tilburg \& Igou, 2017; Westgate \& Wilson, 2018). While boredom rarely co-occurs with positive emotions, it commonly coincides with negative ones, such as loneliness, anger, sadness, and worry, as documented in experience sampling from a large nationally representative sample of U.S. adults (Chin et al., 2017). Environmental features, such as under-stimulation and constraint, may particularly foster the kinds of attention and 
meaning deficits that lead to boredom; indeed, Chin et al. (2017) found that boredom was more often attributable to the situations people were in, rather than to the individuals themselves. In particular, individuals in their sample were highly likely to experience boredom during monotonous or difficult tasks, or when suffering from constraints on their autonomy; similar results are found for students in school settings (Pekrun et al., 2010).

Because attention and meaning are independent causes of boredom, these different causes can result in different experiential types, or "profiles," of boredom (Elpidorou, in press; Westgate \& Wilson, 2018). Deficits in meaning occur when current activities do not match up with currently active valued and salient goals (Baumeister \& Landau, 2018; Van Tilburg \& Igou, 2012, 2013). Such boredom is characterized by increases in arousal and dysphoric affect, altered perceptions of time, and a desire to disengage from the current task (Westgate \& Wilson, 2018). Attention deficits occur when cognitive resources and demands do not match up, most typically in cases of under-stimulation (cf. Raffaelli et al., 2017; Westgate \& Wilson, 2018). Such boredom is characterized primarily by difficulty concentrating and struggling to focus on one's current task (Eastwood, 2012). Thus, boredom can result from a task/situation with high meaning that does not elicit attentional engagement, for example, when reading a relevant scientific article that is highly meaningful for one's own research but is poorly written. Boredom can also result from a task that has low meaning but is attentionally engaging, for instance, a brilliant postdoctoral researcher writing a challenging grant proposal from which s/he will not benefit personally (e.g., writing for a senior supervisor).

Perhaps most common, however, is boredom that results simultaneously from both sources, involving both attention and meaning deficits. Such mixed states (e.g., an experienced worker at an assembly line where s/he lacks meaning and is chronically cognitively understimulated) represent what we might term prototypical boredom (Barret, 2006) - the emotion as it is most often experienced in everyday life and which lay theories best reflect. It is these 
prototypical instances of boredom — often associated with situations offering little challenge and less meaning (Csikszentmihalyi, 2000; van Tilburg \& Igou, 2012)—with which we are most concerned in understanding boredom's relation to sadism as it exists in everyday life.

There is good reason to believe that boredom might contribute to sadistic behavior, as boredom is a powerful motivator of behaviors, both "good" and "bad." Past research has found that boredom associated with meaning deficits results in increased prosocial intentions (Van Tilburg \& Igou, 2017), more ingroup favoritism and outgroup derogation (Van Tilburg \& Igou, 2011), and political polarization (Van Tilburg \& Igou, 2016); moreover, individuals prone to boredom have more positive perceptions of heroes (Coughlan et al., 2019). Consistent with this, religiosity and nostalgia have both been found to reestablish meaning and buffer the negative effects of boredom (Van Tilburg and colleagues, 2013, 2018). Similarly, work on attention deficits in boredom have found that boredom and boredom proneness are associated with greater restlessness and under-arousal (Danckert \& Merrifield, 2018), increased gambling (Mercer \& Eastwood, 2010), and the increased pursuit of novel experiences, even when those experiences are negative (Bench \& Lench, 2019).

In correlational studies, individual differences in trait boredom are related to maladaptive or antisocial interpersonal tendencies, including narcissism (Wink \& Donahue, 1997; and lower Honesty-Humility, Culp, 2006), trait anger, hostility, and aggression (e.g., Dahlen et al., 2004; Isacescu et al., 2017; Joireman et al., 2003; Struk et al., 2017), as well as impulsiveness and lower self-control (Isacescu et al., 2017; Moynihan et al., 2017).

Particularly relevant to our work on sadism is past research suggesting that boredom may indeed foster, in a causal sense, destructive tendencies, targeted inward, or towards oneself. Wilson et al. (2014) found that psychological isolation — spending 15 minutes in a room alone with nothing to do but think — induces boredom and motivates people to harm themselves with electric shocks. Havermans et al. (2015; see also Nederkoorn et al., 2016) reported a similar 
finding; participants watching a boring 60-minute video (an indoor tennis sequence on repeat every 85 seconds, taken from a longer documentary about a Nobel laureate) vs. watching an interesting video for the same time span (the full documentary, including the tennis sequence) substantially increased self-administered electric shocks. Over $90 \%$ of participants shocked themselves in the boring condition, an average of 22 times each.

What all of these studies show is that boredom motivates individuals to change their current situation. In fact, it has been argued that boredom signals a desire for change, with the ultimate goal of remedying the underlying deficits that brought it about (Bench \& Lench, 2019; Van Tilburg \& Igou, 2012; Westgate \& Wilson, 2018; Westgate, 2020). In this regard, boredom fosters behaviors that counter deficits in attention (e.g., gambling, electric shocks), deficits in meaning (e.g., prosocial behavior, ingroup favoritism), or both. From a basic motivational perspective, boredom is an aversive motivational state that motivates action to reduce it. If a primary motivation of bored people is to stop feeling bored, sadistic actions offer one such promising avenue. Indeed, in the following section, we argue that sadistic actions are suited to countering the aversive state of boredom.

\section{On the relation of boredom and sadism}

In his analysis of destructive behavior, psychoanalyst Erich Fromm states: "Man is a passionate being, in need of stimulation; he tolerates boredom and monotony badly and if he cannot take a genuine interest in life, his boredom will force him to seek it in the perverted way of destruction and violence.” (Fromm, 1972, p.9). In fact, Fromm (1973) considered boredom a main source for the development of sadism. A similar point is made by Baumeister and Campbell (1999). In their analysis of evil behavior, they argue that "inflicting harm is likely to be arousing and can perhaps be pleasant, too. As such, it is certainly an antidote to boredom." (p.216). Both Fromm $(1972,1973)$ and Baumeister and Campbell (1999) argue that boredom is an aversive motivational state that motivates people to seek out different activities that involve "stimulation" 
or "arousal and pleasure" (see also Barbelet, 1999; Bench \& Lench, 2013). Since harming others can provide stimulation and excitement (Chester, 2017; Chester et al., 2019; Cikara et al., 2014), we argue that sadism potentially reflects an "antidote to boredom" (Baumeister \& Campbell, 2009, p.216). ${ }^{1}$ As such, we argue that sadism can especially counter boredom stemming from attention deficits, particularly those caused by under-stimulation, as in many prototypical instances of boredom. Such sadistic actions may even become particularly alluring when bored, because boredom increases people's overall reward sensitivity (Milyavskaya et al., 2019), thus shifting the perceived potential emotional benefits of destructive behavior. Of note, we do not postulate that boredom only leads to sadism and not to other stimulating and exciting behaviors. Instead, what we argue is that boredom increases the chance that sadistic behaviors will be chosen, because such behavior remedies the deficit that provoked it.

This is not to say that sadism might not also address meaning deficits. To avoid feelings of meaninglessness when bored, one could instead choose to harm others as an exciting and stimulating distraction to avoid those feelings of meaninglessness. That is, we do not argue that sadism provides meaning per se, as does, for example, engaging in religious practices or nostalgia (Van Tilburg et al., 2013, 2018); we do argue, however, that sadism can reflect a "tool" to avoid feeling meaninglessness. Thus, both attentional and meaning-focused perspectives on boredom result in the same prediction — namely, that boredom motivates acts of sadism.

Before moving to empirical evidence for these predictions, we want to first make clear two points for our readers. First, in the studies that follow, we are concerned with prototypical instances of boredom - that is, boredom as it is most frequently encountered and experienced in everyday life and as is reflected by lay theories about the state (see Seli et al., 2018, who describe

\footnotetext{
${ }^{1}$ We avoid the term "sensation seeking" here, which is defined by "thrill and adventure seeking" and "the need for varied, novel and complex sensations and experiences" (Zuckerman, 1971, p.144). Thus, sensation seeking includes many tendencies such as excitement seeking and seeking out novel experiences. Excitement seeking and seeking out novel experiences both could explain why individuals harm others when being bored. We think, however, that excitement seeking and seeking out novel experiences are two different processes. That is why we assess them separately (cf. Study 9) and refrain from using the term "sensation seeking."
} 
a similar "family resemblances" approach to the myriad types of mind wandering and who recommend that researchers accordingly stipulate the particular type they are studying). In this spirit, we specify that we are interested primarily in prototypical boredom, which consists primarily of mixed states caused by simultaneous deficits in both attention and meaning (Chin et al., 2017; van Tilburg \& Igou, 2012, 2017). Therefore, in the present set of studies, we do not distinguish in our assessment of boredom in the correlational studies (nor in the manipulations of boredom in the experimental studies) between boredom that results from lack of meaning vs. lack of attention. Instead, we assess and induce boredom resulting from both sources. Our main aim in the present work is to explain the emergence of sadism and to test the impact of boredom in this regard - as it is most commonly experienced from an ecologically valid perspective. We do, however, explore in Study 9 which processes (i.e., excitement seeking; novelty seeking; need for meaning) drive the effects of prototypical boredom on sadistic behavior.

Second, we do not argue that boredom makes everyone sadistic. Harming others for pleasure is a severe destructive behavior that might not be in line with private standards (e.g., how a person wants to be) or public standards (e.g., social norms). As such, we should expect boredom to only moderately increase sadism, and we furthermore predict that a majority of individuals will not engage in sadistic behavior, even when bored. Sadistic responses to boredom may be especially common among people who perceive such behavior as available or appropriate alternatives; to address this, we examined individual differences in trait sadism in Studies 7 to 9. In those studies, we test the hypothesis that boredom increases sadistic behavior, particularly among those individuals already high in trait sadism.

\section{Study overview}

In the current paper, we report 9 studies consisting of 15 samples from three different countries, both online and in the lab, using a wide range of methodologies from self-reported individual differences to experimental manipulations of boredom and behavioral measures of 
sadism (e.g., killing worms and intentionally destroying other people's payment). Overall, the paper examines the relationship between boredom and sadism from three different perspectives: first, from a personality perspective by taking into account individual differences in boredom proneness and sadism (Study 1) and showing that boredom proneness relates to sadism, beyond the Big Five and HEXACO personality models, and second, from a societal perspective by demonstrating that boredom is related to sadism across a number of highly important societal contexts (e.g., on the internet, in the military, during child care, and in private fantasies; Studies 2 to 5).

Finally, we adopt an experimental perspective by manipulating boredom and assessing sadistic behavior as its outcome, thus demonstrating a causal effect of boredom on sadistic behavior (Studies 6 to 9). In addition, in Studies 7 to 9, we examine the potential moderating role of dispositional differences in sadism. In Study 7, we show that when given the choice between a sadistic and non-sadistic behavioral option, boredom motivates sadistic behavior only in individuals predisposed to sadism; when sadistic behavior is the only option available (Study 8 and 9), however, boredom increases sadism in individuals, regardless of pre-existing dispositional sadism. Finally, in Study 9, we explore why prototypical boredom promotes sadism. Namely, we examined whether boredom promotes the attention-related mechanisms of seeking out exciting experiences and seeking out novel experiences, and whether boredom elicits the mechanism of meaning seeking. Then we test whether these mechanisms foster sadistic behavior. We show that only excitement seeking and novelty seeking (but not seeking meaningful activities) mediated the effect of the boredom induction on sadistic behavior. In addition, in Study 9 we broaden the perspective and show that boredom not only promotes sadistic (proactive) aggression, but also reactive aggression (i.e., aggression based on a direct provocation by another individual).

In sum, the present research takes important steps to acquire a fundamentally better understanding of both sadism and boredom. So far, past research has largely neglected the causes 
of sadism. In a similar vein, research on boredom has not empirically examined its considerable potential for negative interpersonal consequences. In the present paper, we address both of these gaps in the existing research and highlight important societal contexts where boredom might motivate sadism.

\section{Research ethics statement and data handling}

The studies of the present contribution were run in the United States, Germany, and Denmark. All studies were conducted in full accordance with the Ethical Guidelines of the German Association of Psychologists (DGPs) and the American Psychological Association (APA). Institutional review boards or committees are not mandatory in the countries (Denmark and Germany) where the investigator responsible for all studies was employed (author: SP). Yet, ethical approval for Study 4 and Study 6, which went beyond simple surveys, was obtained (see Method section of Study 4 and Study 6). We made certain that participants were unable to participate twice in the online studies reported in the present contribution. In most of the studies, we also used attention checks to improve data quality ("This is an attention check item. Please answer: I completely agree"). Sample sizes reported in the studies refer to the number of participants who successfully completed all attention check items and finished the study. Data and items of all studies presented in this contribution are available on the Open Science Framework (see https://osf.io/k2swy).

\section{Statistical power}

Using G*Power (Faul et al., 2009), we conducted a power analysis for a two-tailed test to detect at least small to medium effects $(\rho=.25)$ in our correlational studies (Studies 1 to 5). Power was set to .90 (Cohen, 1992). This power analysis revealed a required sample size of $N=160$ to detect a significant effect (alpha level of .05) given the existence of a true effect. However, as we did not know the size of the "true effect," we over-sampled when finances and participant 
accessibility made doing so feasible. The power analyses for the experimental Studies 6 to 9 are described in the respective Method sections.

\section{Study 1: A personality perspective}

The aim of the first study was to put to a correlational test the hypothesis that boredom motivates sadism. The study addressed the question of whether sadistic tendencies are more pronounced among people who report chronic proneness to boredom in everyday life. In addition, we examined whether the relationship between boredom and sadism emerges beyond two prominent personality models, that is, the Big Five and the HEXACO. We also included the Dark Triad of psychopathy, Machiavellianism, and narcissism (Paulhus, \& Williams, 2002; Paulhus, 2014) in our analyses. Note, though, that sadism overlaps, from a personality perspective, with other dark traits (e.g., Bertl et al., 2017; Moshagen et al., 2018). Thus, controlling for other dark traits would remove "meaningful variance" from sadism; in addition, the residual variable (residual sadism) contains less reliable variance than the original variable (sadism) the higher the controlled for variables (the Dark Triad) correlate with the original variable (Lynam et al., 2006; Sleep et al., 2017). As our main research question is the relation between boredom and original sadism, we focused on zero-order correlations between boredom and sadism. For interested readers, we nonetheless inform about the results controlling for the Dark Triad. Miller et al. (2019) recommended using this multivariate approach with care.

\section{Methods}

Procedure. In total, we collected data for six diverse studies (Studies 1A to 1F) from three countries, both online and in the lab. See Table 1 for sample characteristics, as well as means, standard deviations, and Cronbach's $\alpha$ for boredom and sadism. The parameters of all other measures in each study - the Dark Triad, the HEXACO, and the Big Five - are available on the OSF (https://osf.io/k2swy). Labels of all applied scales in this study ranged from $1=$ "I completely disagree" to (depending on the study) 5 or 7 = "I completely agree" (see Table 1 for details). 
Boredom. In all studies, we used the eight-item Short Boredom Proneness Scale (Struk et al., 2017) to measure boredom proneness in everyday life. Two sample items read, "Many things I have to do are repetitive and monotonous" and, "I often find myself at 'loose ends,' not knowing what to do." We used the short version instead of the original Boredom Proneness Scale (BPS; Farmer \& Sundberg, 1986), because the short version has far better psychometric properties, does not suffer from a structurally confounded multi-factor structure (i.e., the multiple factors in the original scale are structurally confounded with reverse-scored items and disappear when this confound is removed), and has fewer conceptual issues (Gana et al., 2019; Struk et al., 2017).

Sadism. Individual differences in sadism were measured using a 5-item version of the Varieties of Sadistic Tendencies scale (VAST; Paulhus \& Jones, 2015) in Study 1A and 1E. The used items read, "I enjoy hurting people"; "I would never purposely humiliate someone" (reversed); "I was purposely mean to some people in high school"; "I dominate others using fear"; and, "I enjoy seeing people suffer." In Studies 1B to 1D and in Study 1F, the 18-item Comprehensive Assessment of Sadistic Tendencies scale (CAST; Buckels \& Paulhus, 2014; Buckels, 2018) was used. The CAST consists of three subscales, including items assessing direct verbal sadism ("I enjoy making jokes at the expense of others"), direct physical sadism ("I enjoy physically hurting people”), and vicarious sadism ("In video games, I like the realistic blood spurts"). The results focusing on the subscales were congruent with the results of the overall scale. For simplicity, we report only the results of the overall scale; results of the subscales can be found on the OSF (see https://osf.io/k2swy).

Dark Triad. In all Studies, the 27-item Short Dark Triad questionnaire (Jones \& Paulhus, 2014; 9 items per dimension) was used to assess narcissism, Machiavellianism, and subclinical psychopathy. All subscales had adequate reliability $(\alpha>.73)$, except for subscales in Study 1E ( $\alpha$ $>$.64), which was conducted in the laboratory without attention check items. 
HEXACO. The HEXACO personality model (Honesty-Humility, Emotionality, Extraversion, Agreeableness, Conscientiousness, Openness) was additionally assessed in Studies 1C, 1E, and 1F. We used the 60-item version of the HEXACO Personality Inventory-Revised (HEXACO-60; Ashton \& Lee, 2009; 10 items per dimension). In all studies, all six dimensions had adequate reliability $(\alpha>.71)$, except for Agreeableness in Study $1 \mathrm{E}(\alpha=.69)$.

Big Five. The Big Five (Neuroticism, Extraversion, Agreeableness, Conscientiousness, Openness) was assessed using the 44-item Big Five Inventory (John et al., 2008) in Study 1B, and the 60-item NEO-FFI (Borkenau \& Ostendorf, 1993) in Study 1D. In both studies, all five dimensions had adequate reliability $(\alpha>.73)$.

Participants. In two instances we fell short of the threshold set by our power analysis described above: Due to a programming error in Study 1E, we did not obtain values in psychopathy for $n=74$ (out of 192 initial) participants, leaving 118, and in Study $1 \mathrm{~F}$ the small sample size $(n=77)$ was determined by a restricted pool of participants. See Table 1 for the number of participants in each study as well as descriptives for age and gender. ${ }^{2}$

\section{Results and Discussion}

As displayed in Table 1, analyses revealed significant positive correlations between boredom and sadism in all six studies, ranging from $r=.30$ (a medium effect) to $r=.53$ (a large effect; categorization of effect sizes is based on Cohen (1992). To calculate the overall effect size, we computed a random-effects internal meta-analysis. This analysis revealed an overall correlation between boredom and sadism of $r=.37, p<.001$ (see Table 2 ).

Next, we tested whether the relation between boredom and sadism emerged beyond the Dark Triad, the HEXACO, and the Big Five. The following effect sizes are based on randomeffects internal meta-analyses. Controlling for the Dark Triad, boredom continued to statistically predict sadism $\left(r_{\text {partial }}=.20, p<.001\right)$; a similar pattern emerged when controlling for personality

\footnotetext{
${ }^{2}$ Results of the HEXACO are also reported in Pfattheicher, Schindler, and Nockur (2019); the results including boredom are only reported in the present contribution.
} 
$\left(\right.$ HEXACO: $r_{\text {partial }}=.28, p=.001$; Big Five: $\left.r_{\text {partial }}=.26, p<.001\right)$. Detailed results, including multivariate regression analyses predicting sadism while controlling for the personality models, can be found on the OSF (https://osf.io/k2swy). The association between boredom and sadism remains robust $(r=.32, p<.001)$ when controlling for gender and age (as was the case for the other studies reported in this paper). 
Table 1. Overview of sample characteristics in Study 1 and the correlation (Pearson's $r$ ) between trait boredom and sadism

\begin{tabular}{|c|c|c|c|c|c|c|c|c|c|c|c|c|c|c|}
\hline \multirow[b]{2}{*}{ Study } & \multirow[b]{2}{*}{ Country } & \multirow[b]{2}{*}{ Locale } & \multirow[b]{2}{*}{$N$} & \multirow[b]{2}{*}{$M_{\text {age }}$} & \multirow[b]{2}{*}{$S D_{\text {age }}$} & \multirow[b]{2}{*}{$\%$ women } & \multirow{2}{*}{$\begin{array}{l}\text { Scale } \\
\text { range }\end{array}$} & \multicolumn{2}{|c|}{ Boredom } & \multicolumn{4}{|c|}{ Sadism } & \multirow[b]{2}{*}{ Correlation $^{\mathrm{a}}$} \\
\hline & & & & & & & & Mean & $S D$ & $\alpha$ & Mean & $S D$ & $\alpha$ & \\
\hline Study 1A & U.S. & online (MTurk) & 200 & 38.2 & 13.1 & 48.0 & $1-7$ & 2.64 & 1.35 & .91 & 1.55 & 0.88 & .71 & .46 \\
\hline Study 1B & U.S. & online (MTurk) & 195 & 37.0 & 10.7 & 47.7 & $1-7$ & 2.56 & 1.31 & .91 & 2.25 & 0.96 & .87 & .40 \\
\hline Study 1D & Germany & online (Clickworker) & 205 & 38.8 & 12.9 & 47.8 & $1-7$ & 2.81 & 1.29 & .90 & 2.03 & 0.80 & .86 & .34 \\
\hline Study $1 \mathrm{E}$ & Germany & offline (lab) & 118 & 22.4 & 3.4 & 53.4 & $1-5$ & 2.29 & 0.84 & .86 & 1.49 & 0.59 & .70 & .41 \\
\hline Study $1 \mathrm{~F}$ & Denmark & offline (classroom) & 77 & n.a. & n.a. & n.a. & $1-5$ & 2.13 & 0.64 & .76 & 1.50 & 0.61 & .90 & .53 \\
\hline
\end{tabular}

Note. Due to anonymity reasons, we did not assess age and gender in Study 1E; ${ }^{a}$ for all correlations, $p<.001$; labels of the scales ranged from "I completely disagree" to "I completely agree." Higher means indicate stronger boredom proneness and stronger sadistic tendencies. 
In summary, the results of the first study support the hypothesis that sadistic tendencies are more likely to emerge among people prone to boredom in everyday life. Here, we want to emphasize that the positive relationship between boredom and sadism was robust across three different countries and across sample source: online, in the lab, and in the classroom. We further show that (1) the correlation between boredom and sadism is not simply due to personality as measured by the Big Five and the HEXACO, and (2) the correlation is not due to general negative affect, as the correlation emerged beyond neuroticism, which is the indicator of general negative affect in personality (e.g., Miller et al., 2009).

Of note, the correlations between additionally assessed variables (see Table 2) were similar to previous studies; HEXACO dimensions were correlated with the Dark Triad to a similar extent as in a recent meta-analysis (Muris et al., 2017). Moreover, boredom was related to the HEXACO dimensions, much as reported in Culp (2006). That our findings are congruent with, and replicate, past literature supports the validity of the present study.

However, Study 1 relies on correlational data; we cannot conclude whether everyday boredom in life promotes sadism (in a causal sense), or whether sadists report higher boredom levels due to a heightened sensitivity to boredom. We experimentally examine causality in Studies 6 through 9, which support the first explanation: that boredom is a cause, and not merely a correlate or consequence, of sadistic behavior. However, in the next several studies, 2 through 5 , we first examine our basic hypothesis — that boredom motivates sadism—-from a societal perspective by testing the relationship between boredom and sadism across a variety of highly relevant and ecologically valid contexts. We start with the relationship of boredom with online trolling for fun, that is, sadism on the internet. 
Table 2. Pooled correlations based on random-effects internal meta analyses between the assessed constructs across Studies $1 \mathrm{~A}-1 \mathrm{~F}$

\begin{tabular}{|c|c|c|c|c|c|c|c|c|c|c|c|c|}
\hline & & (1) & $(2)$ & (3) & (4) & (5) & (6) & $(7)$ & $(8)$ & $(9)$ & $(10)$ & (11) \\
\hline (1) & Boredom & 1.00 & & & & & & .57 & -.43 & -.41 & -.58 & -.19 \\
\hline (2) & Sadism & .37 & 1.00 & & & & & .11 & -.02 & -.56 & -.34 & -.08 \\
\hline (3) & Machiavellianism & .33 & .46 & 1.00 & & & & .15 & -.18 & -.52 & -.16 & -.02 \\
\hline (4) & Narcissism & -.03 & .32 & .34 & 1.00 & & & -.23 & .46 & -.11 & .12 & .16 \\
\hline (5) & Psychopathy & .35 & .67 & .56 & .40 & 1.00 & & .18 & -.09 & -.58 & -.35 & -.09 \\
\hline (6) & Honesty-Humility & -.26 & -.47 & -.48 & -.45 & -.53 & 1.00 & & & & & \\
\hline (7) & Emotionality/Neuroticism ${ }^{1}$ & .09 & -.25 & -.14 & -.21 & -.27 & .12 & 1.00 & -.47 & -.34 & -.45 & -.11 \\
\hline & Extraversion & -.43 & -.04 & -.13 & .48 & -.06 & -.05 & -.19 & 1.00 & .37 & .39 & .16 \\
\hline (9) & Agreeableness & -.25 & -.34 & -.38 & -.20 & -.45 & .41 & .01 & .15 & 1.00 & .43 & .18 \\
\hline (10) & Conscientiousness & -.48 & -.25 & -.14 & .07 & -.31 & .18 & .06 & .25 & .10 & 1.00 & .18 \\
\hline (11) & Openness & -.15 & -.08 & -.06 & .12 & -.07 & .12 & -.05 & .10 & .09 & .17 & 1.00 \\
\hline
\end{tabular}

Note. ${ }^{1}$ Emotionality from HEXACO refers to Neuroticism from the Big Five; the correlations below the diagonal refer to the

HEXACO, the correlations above the diagonal refer to the Big Five; correlations involving the Dark Tetrad are based on $N=1780$; correlations involving the HEXACO are based on $N=1180$; correlations involving the Big Five are based on $N=399$. All correlations above $r=|.16|$ are significant at $p<.05$. 


\section{Study 2: Online trolling}

Past research revealed sadism to be a driving motivation for harming others for fun on the internet (Buckels et al., 2014, 2019; March, 2019; Moor \& Anderson, 2019; Paananen \& Reichl, 2019; Sest \& March, 2017; van Geel et al., 2017). In line with our main hypothesis that boredom motivates sadism, in this study we tested whether sadistic tendencies on the internet are more likely to emerge among people chronically prone to boredom in everyday life. Accordingly, in Study 2 and in addition to boredom proneness, we also assessed online trolling. We also tested whether these relationships hold beyond the HEXACO personality model.

\section{Methods}

Procedure and Participants. The study was collected online using a sample from the U.S. obtained via Amazon Mechanical Turk. We obtained full responses from $N=196\left(M_{\text {age }}=38.5\right.$, $S D_{\text {age }}=11.2,56.3 \%$ women). A 5-point Likert scale was used (range 1-5), ranging from $1=$ "I completely disagree" to 5 = "I completely agree."

Boredom. As in Study 1, we used the 8-item Short Boredom Proneness Scale (Struk et al., 2017) to measure boredom proneness in life.

Trolling. We used the 4-item Global Assessment of Internet Trolling (GAIT) scale to measure online trolling (Buckels et al., 2014). Two sample items read, "I have sent people to shock websites for the lulz" and, "I like to troll people in forums or the comments section of websites" $(M=1.49, S D=0.81, \alpha=.84)$.

HEXACO. The HEXACO personality model was assessed as in Study 1 using the 60 -item version of the HEXACO Personality Inventory-Revised (HEXACO-60; Ashton \& Lee, 2009). All six dimensions had adequate reliabilities $(\alpha>.73)$. 


\section{Results and Discussion}

Testing our central assumption, analysis revealed a medium-size positive correlation between boredom and trolling, $r(195)=.34, p<.001$. Controlling for HEXACO, boredom was still related to trolling $\left(r_{\text {partial }}(189)=.17, p=.016\right)$.

These findings support the idea that boredom is associated with sadism on the internet; we showed that trolling is more likely when people report chronic proneness to boredom. Given that trolling can have severe psychosocial consequences for targeted individuals (Olweus \& Limber, 2018), the present study points to one potential cause of sadistic behavior on the internetboredom. We want to acknowledge, however, that we did not assess other online behaviors in this study. Thus, it remains unclear whether boredom also relates to other online behavior, and whether boredom motivates going online in general. In the next study, we move to another important context — that is, boredom and sadism in the military.

\section{Study 3: Sadism in the military}

Modern military missions (at home and abroad) entail long periods of waiting for tasks, training, or missions; hence, boredom can be prevalent among soldiers (Bartone, 2006; Raab, 2012). At the same time, cruel behavior can happen - targeted at the enemy but also towards fellow soldiers (Hernandez, 2015; Wither, 2006). In the present study, we investigated the relation between boredom proneness during one's time in the military and sadism towards fellow soldiers. Our primary research question was whether sadistic tendencies in the military are more likely among soldiers reporting greater boredom during their time in service. Accordingly, we assessed boredom during military service and sadism towards one's fellow soldiers.

\section{Methods}

Procedure. The study was conducted online using a sample from the U.S. obtained via Amazon Mechanical Turk. Via the pre-screening system in Amazon Mechanical Turk, the study was only accessible by participants with a history in the U.S. military; these participants had 
previously indicated in the Amazon Mechanical Turk system that they have military experience, independent of (and prior to) the present study. That is, participants were screened for previous military experience prior to participating.

We first collected demographic background data (age, gender, nationality) and general information about the participants (their current military status). We then assessed items measuring boredom and sadism in the military. Before participants were presented with the items, they read, "In the following, we want to ask you a few questions about your time in the military. We want you to answer the questions regarding your last service section in the military. The term 'last service section' means the last period of time (e.g., three months) when you served in the military (e.g., as fire support specialist) in a specific military operation (e.g., Afghanistan) or on a military base." Finally, we assessed whether or not their last service section in the military was an overseas assignment, their military rank during that time, where they were stationed (the country), and during what time span. In the end, participants could leave a comment on the study.

Participants. We sampled full responses from $N=289$ individuals $\left(M_{\text {age }}=43.6, S D_{\text {age }}=\right.$ 14.0, 30.1\% women). A 5-point Likert scale was used (range 1-5), ranging from $1=$ "I completely disagree" to 5 = "I completely agree."

Sample characteristics. In line with previous work on military samples, we assessed status information of our participants to describe our sample (Lancaster \& Erbes, 2017). We assessed what kind of soldiers our participants were $(86.9 \%$ regular soldiers serving for a fixed term, $9.3 \%$ professional soldiers, $3.8 \%$ other $)$. We measured their current status $(10.7 \%$ active duty for the military, $9.7 \%$ retired, $75.8 \%$ honorably discharged, $3.8 \%$ other) and their status at the time of service ( $81.0 \%$ active duty, $9.7 \%$ reserves, $6.9 \%$ national guard, $2.7 \%$ other $)$. Of those, $47.8 \%$ served in the Army, $19.4 \%$ in the Air Force, $22.8 \%$ in the Navy, $9.0 \%$ in the Marines, $0.7 \%$ in the Coast Guard. During their time in the military, $65.1 \%$ had at least one overseas assignment. 
Boredom. We adapted the Short Boredom Proneness Scale (Struk et al., 2017) to the military context. Two sample items of the scale read, "During my time in the military, I found it hard to entertain myself" and, "I was often bored during my time in the military" $(M=2.15, S D=$ $0.96, \alpha=.88$ ). All items can be found on the OSF (see https://osf.io/k2swy).

Sadism. We adapted the Comprehensive Assessment of Sadistic Tendencies scale (CAST; Buckels \& Paulhus, 2014; Buckels, 2018) to the military context $(M=1.59, S D=0.68, \alpha=.87)$. We assessed the two subscales of direct verbal sadism ("During my time in the military, I enjoyed making jokes at the expense of my comrades") and direct physical sadism ("I enjoyed physically hurting my comrades"). We did not assess vicarious sadism, because the initial items were difficult to adapt to the military context (e.g., "In video games, I like the realistic blood spurts"), although in hindsight we could have created a new vicarious subscale (e.g., "I liked to watch when there was a physical fight between my comrades"). The results focusing on the two assessed subscales were congruent with the results of the overall scale. ${ }^{3}$

\section{Results and Discussion}

As predicted, we found a positive correlation between boredom and sadism, $r(277)=.23, p$ $<.001$, representing a small to medium size effect. ${ }^{4}$ Overall, this study suggests that boredom might motivate sadism in the military context; we showed that sadistic tendencies towards fellow soldiers were more likely to emerge when military service personnel reported experiencing greater boredom during their time in the military. Of note, the present study has several limitations: It is non-representative, correlational, and based on retrospective self-reports. However, it points to an important context where boredom might stimulate sadism — namely, the military. In the next

\footnotetext{
${ }^{3}$ We also assessed the Bully Participant Behaviors Questionnaire (BPBQ; Demaray et al., 2014), adapted to the military context. Bullying was significantly correlated with boredom $(r(277)=.19 ; p=.001)$.

${ }^{4}$ Given that we assessed information about where participants were stationed (the country) during their last time of service and during which period of time, we could also categorize whether participants' self-reported boredom and sadism levels refer to a period where they were stationed in a violent conflict (Heidelberg Institute for International Conflict Research, 2019). The relation between boredom and sadism occurred in both violent and non-violent conflict areas, as well as when soldiers were stationed in the U.S.
} 
study, we move to another important but different context — that is, sadism in parents while caring for their children.

\section{Study 4: Sadism during child care}

In their extensive review on the prevalence of child maltreatment, Stoltenborgh et al. (2015) conclude that "child maltreatment is a widespread, global phenomenon affecting the lives of millions of children all over the world" (p.37). Thus, it is an important issue, from a societal perspective, to investigate factors that might promote child maltreatment.

In the present study, we examine one specific form of child abuse, that is, harming one's own child for pleasure. Sadism towards one's own child can manifest in various forms, including verbal sadism, when parents enjoy making jokes at the expense of their child; physical sadism, when parents enjoy physically hurting their child; and, vicarious sadism, when parents are amused by others mocking or teasing their child. We investigated the relationship between boredom experienced during child care and sadism towards one's own child. Our primary research question in this study was whether sadistic tendencies during child care are more likely when experiencing boredom. Accordingly, in Study 4, we assessed parents' sadism towards their own children and self-reported boredom during child care.

\section{Methods}

Procedure and participants. Ethical approval for the study was obtained from the Research Ethics Board at University of Kassel, Germany. The study was conducted online, using a sample from native English-speaking countries (e.g., the U.S., Canada, UK) obtained via Prolific. Via the pre-screening system in Prolific, only parents with a least one child who was between 0 to 18 years old, and who lived at home, could participate in the study. We obtained full responses from $N=300$ parents $\left(M_{\text {age }}=37.9, S D_{\text {age }}=7.6,69.0 \%\right.$ women $)$. A 5-point Likert scale was used to assess boredom and sadism (range 1-5), ranging from $1=$ "I completely disagree" to 5 = "I completely agree." In the study it was stated that parents should answer the items with respect to 
their youngest child, in case they had more than one. In order to test the relation between boredom and sadism beyond additional demographic variables, we also assessed age and gender of the youngest child, number of children, household size, education (on a scale with six possibilities ranging from "no formal education" to "Doctorate degree [PhD/MD/other]"), and household income (using 12 categories).

Boredom. Boredom was measured in two different ways. First, as in Study 1, we used the eight-item Short Boredom Proneness Scale (Struk et al., 2017) to measure boredom proneness in life. Second, we adapted the Short Boredom Proneness Scale to the child care context (e.g., the original item "I often find myself at 'loose ends,' not knowing what to do" was changed to "When watching my child, I often don't know what to do with myself'). All items are provided on the OSF (see https://osf.io/k2swy).

Sadism. Sadism was also measured in two different ways. First, as in Study 1, the 18-item Comprehensive Assessment of Sadistic Tendencies scale (CAST; Buckels \& Paulhus, 2014; Buckels, 2018) was used. Second, we adapted the CAST to the child context. The items assessing direct verbal sadism could be easily adapted to the child context, thus, "I enjoy making jokes at the expense of others" was changed to "Sometimes, I enjoy making jokes at the expense of my child," and for direct physical sadism, "I enjoy physically hurting people" was changed to "To be honest, I have enjoyed physically hurting my child."5 Vicarious sadism ("In video games, I like the realistic blood spurts") had to undergo a major change. We developed six new items (e.g., "Sometimes I find it amusing when others mock or tease my child"; "I have found it entertaining when my child got into physical or verbal fights with others"; "Sometimes I enjoy watching my child being reprimanded by another adult"). All subscales were reliable $(\alpha \mathrm{s}>.79)$ and strongly correlated with each other $(r \mathrm{~s}>.59$, all $p \mathrm{~s}<.001)$. The results focusing on the subscales were congruent with the results of the overall scales. For simplicity, we only report the results of the

\footnotetext{
${ }^{5}$ To reduce social desirability and item difficulty, we used modifiers such as "Sometimes, ...", "To be honest, ...", and "Occasionally, ..." when assessing sadism towards one's child.
} 
overall scales. We refer to "general sadism" when using the CAST and "sadism during child care" when using the adapted version. Results of the subscales can be found on the OSF (see https://osf.io/k2swy).

\section{Results and Discussion}

Looking at the descriptive statistics, we found relatively low levels of boredom and sadism during child care. Due to the severity of sadism during child care, this was expected. Nonetheless, there was variance on all measures, which co-varied as expected (all zero-order correlations can be found in Table 3): Overall boredom in everyday life, and boredom during child care, were both related to sadism during child care. The correlation between child-directed sadism and boredom during child care $(r(298)=.28, p<.001)$ was significantly stronger $(p=.01)$ than the correlation between child-directed sadism with boredom in everyday life $(r(298)=.16, p=.005)$. That is, the specific measure of boredom (boredom during child care) was better able than the general measure of boredom (overall boredom during everyday life) to predict the specific outcome of interest (sadism during child care). Of note, the correlations between the two boredom measures and sadism during child care remained robust in terms of effect size and significance levels, even after controlling for all assessed demographical variables (detailed results can be found on the OSF, see https://osf.io/k2swy). They also persisted after bootstrapping all analyses. 
Table 3. Means, standard deviations, Cronbach's alphas, and zero-order correlations of the applied scales in Study $4(N=300)$

\begin{tabular}{|c|c|c|c|c|c|c|c|c|}
\hline & & $M$ & $S D$ & $\alpha$ & (1) & (2) & (3) & (4) \\
\hline (1) & Boredom in life & 2.41 & 0.81 & .88 & 1.00 & & & \\
\hline (2) & Boredom during child care & 1.93 & 0.84 & .90 & .55 & 1.00 & & \\
\hline (3) & General sadism & 1.47 & 0.54 & .89 & .27 & .21 & 1.00 & \\
\hline (4) & Sadism during child care & 1.19 & 0.36 & .91 & .16 & .29 & .56 & 1.00 \\
\hline
\end{tabular}

These results support our prediction that boredom during child care might motivate sadism towards one's own child; we found that sadism during child care was more likely to be reported among parents who felt bored while caring for their children. Zooming in, we show our contextually specific measure of boredom (i.e., boredom during child care) was better than our general measure of boredom (i.e., overall boredom during everyday life) at predicting our specific outcome of interest (i.e., sadism during child care). Thus, this study is valuable in showing that, as in attitudes, more contextually specific measures of emotions (e.g., boredom) are better able to predict contextually specific sadistic behavior (Davidson \& Jaccard, 1979). Furthermore, given that child maltreatment can have severe psychosocial consequences for targeted children (Stoltenborgh et al., 2015), the present study points to a potential cause of child maltreatment that has not so far been considered in empirical research. We want to acknowledge, however, that we did not address other non-normative behaviors in this study, nor can we test whether the relationship emerges because boredom is related to a generalized tendency to report nonnormative behaviors or to a dislike of children.

At this point, we also wish to address the issue of social desirability, given the nature of the assessed constructs. It is reasonable to expect that those willing to self-report high levels of boredom and of sadism in child care are likely to be individuals relatively less concerned with 
social desirability or impression management. From that perspective, it is possible that boredom and sadism are correlated due to method variance - individuals scoring high on boredom and on sadism due to a willingness to endorse items suggesting socially undesirable tendencies.

So far, we have seen that individual differences in boredom predict overall sadistic tendencies, sadism on the internet (online trolling), sadistic behavior in the military (among servicemen and women), and sadistic behavior towards one's children (among parents). In the next study, we consider one final important context - that is, boredom and the sadistic fantasy of shooting somebody for fun.

\section{Study 5A and 5B: Sadistic fantasies}

In this study, we tested whether sadistic fantasies are more likely among people who report chronic proneness to boredom in their everyday life. Here, we focus on the sadistic fantasy of shooting somebody for fun. While this might seem farfetched, it is reported that a surprising number of shootings (and other acts of violence) are carried out by perpetrators "out of boredom." For instance, an Irish teen who was recently caught aiming his gun at drivers from an overpass explained that he did so because he was "bored and messing" (Ferguson \& McLean, 2019).

In Study 5B, we additionally ask about other fantasies that are destructive but less sadistic (i.e., "robbing a bank"; "paying back someone who has hurt you"). In this way, we can test whether boredom relates not only to sadistic fantasies (shooting somebody for fun), but also to the antisocial fantasy of robbing a bank, or to a fantasy involving reactive aggression ("paying back someone who has hurt you").

\section{Methods}

Procedure and participants. Studies 5A and 5B were conducted online using samples from the U.S. obtained via Amazon Mechanical Turk. We deliberately over-sampled our power analysis to obtain data from a sufficient number of gun owners (see footnote 6) and obtained full responses from $N=477$ in Study 5A ( $M_{\text {age }}=35.6, S D_{\text {age }}=12.5,54.5 \%$ women $)$. Study 5B materials, sample 
size (500 participants), exclusion criteria, hypotheses, and data analysis were pre-registered on aspredicted.org. The pre-registration is accessible on the OSF (https://osf.io/k2swy). We obtained full responses from $N=500\left(M_{\text {age }}=38.6, S D_{\text {age }}=12.9,49.6 \%\right.$ women $)$.

Boredom. As in the previous studies, we used the eight-item Short Boredom Proneness Scale (Struk et al., 2017) to measure boredom proneness in everyday life (Study 5A, $\alpha=.92$; Study 5B, $\alpha=.92$ ). A 7-point Likert scale was used (range 1-7) from $1=$ "I completely disagree" to $7=$ "I completely agree." For descriptives, see Table 4.

Sadistic fantasies. In both studies, after participants completed the boredom items, on the next page, they read, "People can have very different and diverse fantasies. We are interested in your fantasies." Participants were asked to indicate on a 7-point Likert scale ranging from "never" to "regularly" whether they fantasize about "being rich," "being fluent in a different language," "shooting somebody for fun," "flying," "being a rock star," and "working in a job I really like." In Study 5b, we added three additional fantasies: "robbing a bank," "having exciting sexual intercourse," and "paying back someone who has hurt you."

The non-sadistic fantasies were generated from an initial pilot pre-study where we asked individuals to describe their fantasies in an open-response format (see https://osf.io/k2swy for the list of fantasies). To reduce demand characteristics, the sadistic fantasy item ("shooting somebody for fun") was placed in between other fantasies.

\section{Results and Discussion}

All zero-order correlations are displayed in Table 4. We found in both studies, as expected, a positive correlation between boredom and the sadistic fantasy of "shooting someone for fun," Study 5a: $r(475)=.43, p<.001$; Study 5b: $r(498)=.46, p<.001 .^{6}$ These correlations were significantly higher (all $p \mathrm{~s}<.05$ ) than the correlation between boredom and "being rich," "being fluent in a different language," "flying," "being a rock star," "working in a job one really likes,"

${ }^{6}$ Given that it is far easier for gun owners to transform such fantasies into action, in Study $5 \mathrm{~A}$ we also assessed whether participants owned a gun $(21.4 \%$, that is, $n=102)$. Boredom was reliably related to sadistic fantasies across both gun owners $(r(100)=.38, p<.001)$ and non-gun owners $(r(373)=.44, p<.001)$. 
and "having exciting sexual intercourse." The correlation between boredom and sadistic fantasies was only barely more significant than with "robbing a bank" $(p=.064)$ and not significantly different from "paying back someone who has hurt you" $(p=.333)$. When controlling for all other fantasies (to control for general fantasizing), boredom was in both studies still correlated with "shooting someone for fun" (Study 5A: $r=.33, p<.001$; Study 5B: $r=.25, p<.001$ ). 
Table 4. Means, standard deviations, and zero-order correlations of the applied scales in Study 5A $(N=477)$ and in Study 5B $(N=500)$

\begin{tabular}{|c|c|c|c|c|c|c|c|c|c|c|c|c|c|c|c|}
\hline & & \multicolumn{2}{|c|}{ Study 5a } & \multicolumn{2}{|c|}{ Study $5 b$} & \multirow[b]{2}{*}{$(1)$} & \multirow[b]{2}{*}{$(2)$} & \multirow[b]{2}{*}{$(3)$} & \multirow[b]{2}{*}{ (4) } & \multirow[b]{2}{*}{$(5)$} & \multirow[b]{2}{*}{ (6) } & \multirow[b]{2}{*}{$(7)$} & \multirow[b]{2}{*}{$(8)$} & \multirow[b]{2}{*}{$(9)$} & \multirow[b]{2}{*}{$(10)$} \\
\hline & & $M$ & $S D$ & $M$ & $S D$ & & & & & & & & & & \\
\hline (1) & Boredom & 3.14 & 1.44 & 3.01 & 1.44 & 1 & .25 & .21 & .46 & .22 & .27 & .13 & .40 & .19 & .42 \\
\hline (2) & Being rich & 5.09 & 1.68 & 5.10 & 1.69 & .20 & 1 & .15 & .11 & .16 & .16 & .19 & .12 & .33 & .25 \\
\hline (3) & Being fluent in a different language & 3.73 & 1.98 & 3.73 & 1.97 & .21 & .19 & 1 & .25 & .29 & .22 & .26 & .20 & .11 & .17 \\
\hline (4) & Shooting somebody for fun & 1.51 & 1.33 & 1.53 & 1.34 & .43 & .03 & .23 & 1 & .27 & .35 & .04 & .67 & .12 & .44 \\
\hline (5) & Flying & 3.19 & 2.06 & 3.42 & 2.01 & .27 & .21 & .25 & .24 & 1 & .40 & .18 & .32 & .28 & .25 \\
\hline (6) & Being a rock star & 2.83 & 2.00 & 2.78 & 1.94 & .34 & .21 & .24 & .41 & .40 & 1 & .13 & .35 & .21 & .33 \\
\hline (7) & Working in a job I really like & 5.36 & 1.65 & 5.20 & 1.78 & .24 & .34 & .22 & .12 & .17 & .19 & 1 & .04 & .20 & .12 \\
\hline (8) & Robbing a bank & n.a. & n.a. & 1.67 & 1.36 & n.a. & n.a. & n.a. & n.a. & n.a. & n.a. & n.a. & 1 & .21 & .53 \\
\hline (9) & Having exciting sexual intercourse & n.a. & n.a. & 4.67 & 2.02 & n.a. & n.a. & n.a. & n.a. & n.a. & n.a. & n.a. & n.a. & 1 & .26 \\
\hline$(10)$ & Paying back someone who has hurt you & n.a. & n.a. & 2.80 & 1.93 & n.a. & n.a. & n.a. & n.a. & n.a. & n.a. & n.a. & n.a. & n.a. & 1 \\
\hline
\end{tabular}

Note. A 7-point Likert scale was used (range 1-7). Correlations below the diagonal refer to Study 5A; correlations above the diagonal refer to Study 5B. All correlations $r>.13$ are significant at $p<.05$ 
Overall, Study 5 showed that fantasies are more likely among people experiencing chronic proneness to boredom in everyday life. This was particularly true of the sadistic fantasy of shooting somebody for fun. Interestingly, boredom was also strongly related to the antisocial fantasy of robbing a bank and to a fantasy involving reactive aggression (i.e., retaliating against past bad behavior). Thus, this study provides first evidence that boredom relates not only to sadistic tendencies, but also to other destructive or aggressive tendencies. We recapture this interesting finding in Study 9 where we experimentally test whether boredom not only promotes sadistic (proactive) aggression, but also reactive aggression (i.e., aggression after a provocation).

In sum, across five studies totaling more than 3500 participants, we see that individual differences in boredom reliably predict sadism across a wide variety of important societal contexts: in everyday life, online, in the military, at home with one's own children, and even in people's private fantasy lives. With this, we close the section on individual differences and generalizability across societally relevant contexts and move forward to the question of causality. Is boredom actually causing sadism? In the next four studies, we adopt a causal analytic approach and test this relationship experimentally by manipulating boredom. In addition, we move beyond self-report to measure real sadistic behavior towards human and non-human individuals.

\section{Study 6: Worm killing}

In Study 6, we used a bug-killing paradigm used in previous research to assess sadistic behavior (Buckels et al., 2013; Martens et al., 2007; Lobbestael et al., in press). In this paradigm, individuals can (ostensibly) kill other real, living creatures by shredding them in a modified coffee grinder. In the present study, we used an experimental manipulation to induce boredom, and then gave participants the option to kill, as detailed below. Thus, Study 6 used an experimental design and causal analytical approach to test the assumption that boredom itself motivates sadistic behavior. 


\section{Methods}

Participants. We maximized sample size within the constraints imposed by provided resources at the time the study was conducted (in terms of money, access to participants, and the help of student research assistants). We were able to obtain complete data from 129 participants $\left(M_{\text {age }}=35.1, S D_{\text {age }}=12.5,54.1 \%\right.$ women $)$. With this sample size and a dichotomous dependent variable (a participant shredded worms vs. did not), we had a statistical power of .81 to detect an increase of shredding of, for instance, $1 \%$ to $14 \%$ with an error probability of .05 (two-tailed).

Procedure. The study was conducted in a German university lab. Ethical approval for the study was obtained from the Research Ethics Board at Ulm University, Germany. Upon arrival, research assistants first removed (with consent) all personal belongings that could distract participants during the boredom induction (e.g., reading material, laptops, bags, phones). Participants then entered the lab. In the lab, there were four cubicles where individuals could work alone, in private and unseen by others on the study. The experimenter was also placed outside the lab. Participants first read an introduction to the study and were then randomly assigned to either the boredom condition or the control condition. In both conditions, participants watched a 20minute video (randomly assigned). While watching the video, participants could engage in “killing” worms. Finally, participants completed self-report items assessing their (sadistic) affect. After completing the study, participants received 5 Euros (about 5.56 US dollars) and a chocolate bar as compensation for participating in the study.

Boredom. We induced boredom by randomly assigning participants to watch one of two versions of a video. A typical boredom manipulation involves working on a monotonous and repetitive task (e.g., copying 10 references; Van Tilburg et al., 2013); the dependent variable is then assessed after the end of the boredom manipulation. These typical manipulations confound the experience of boredom with the end (and relief) of this very experience. To circumvent this issue, we used an on-line boredom induction during which participants could engage in killing 
worms (following previous research, see Nederkoorn et al., 2016). Specifically, in the boredom condition $(n=67)$, participants watched a 20 -minute video of a waterfall. Nothing else happened in this video. In the control condition $(n=62)$, participants instead watched a 20 -minute video documentary about the Alps.

Worm killing. We implemented the bug-killing paradigm used in previous research to assess sadistic behavior (Buckels et al., 2013; Martens et al., 2007; Lobbestael et al., in press). Instead of bugs we used small living worms, specifically maggots $(3-4 \mathrm{~mm})$ from the green bottle fly Lucilia Sericata. In the introduction of the study, participants were informed that they would watch a 20-minute video. They then read, "While watching the video, you have the opportunity to shred worms. For this task, you will find one worm in each of the three cups in front of you. If you feel like it, you can put the worms in the machine and shred them while watching the video. To do so, press the button on the machine. Some participants do, others don't." The machine was a modified coffee grinder. The worms were given names (Toto, Tifi, Kiki) to humanize them, and to make the behavior even crueler (Buckels et al., 2013). A barrier within the machine prevented the worms from actually being killed so they could be set free after the experiment; thus, no worms were harmed in the study. Participants were unaware of this at the time, but all participants were debriefed after the experiment and asked to not inform others of this aspect of the study. 

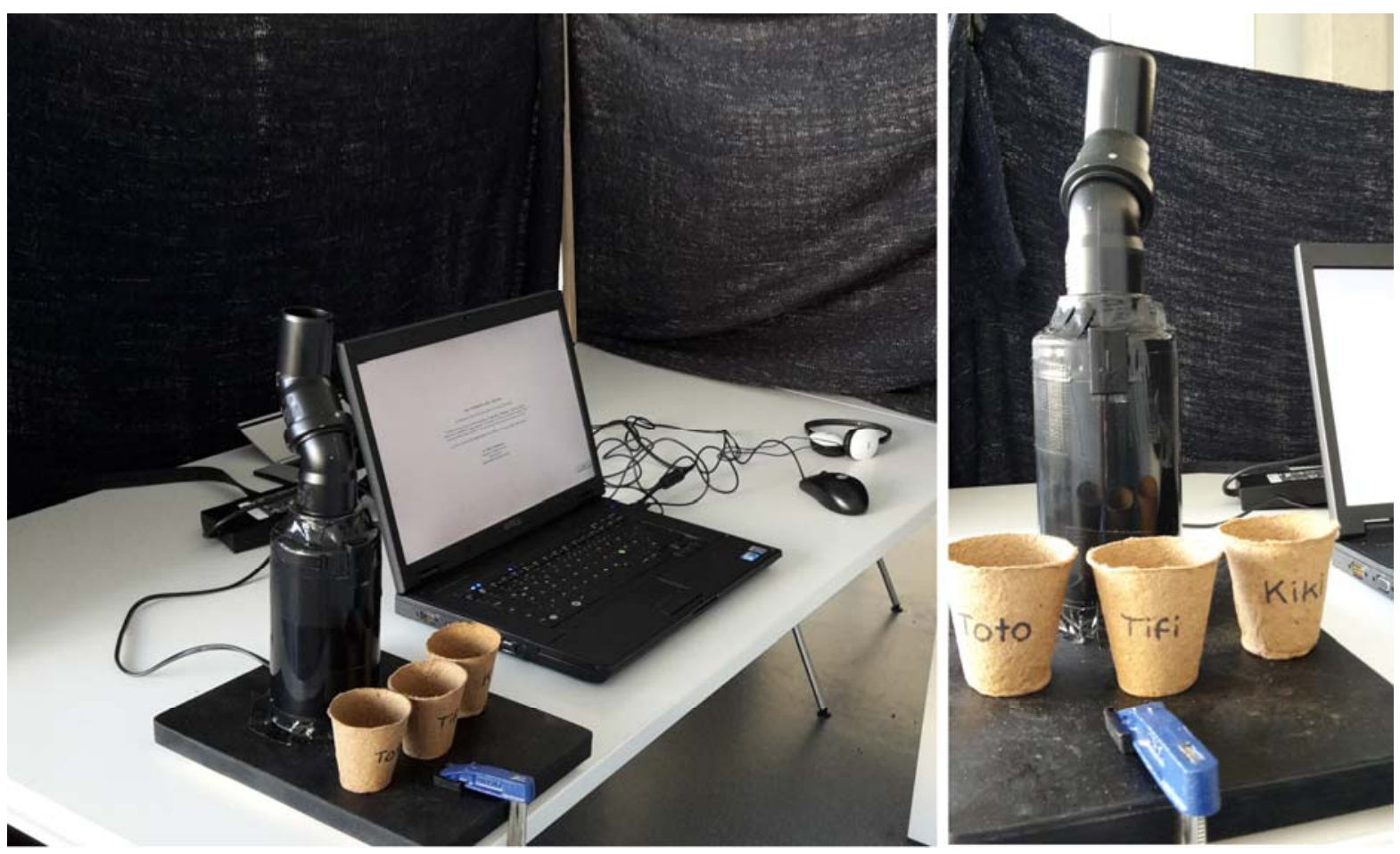

Figure 1. The setup in Study 6 (left picture) and the worm-killing machine as well as the three cups with the worms inside (right picture)

Affect. After the video ended, participants' affective state while watching the video was assessed retrospectively. Specifically, participants responded to an adapted version of the Short Positive and Negative Affect Schedule (short PANAS; Mackinnon et al., 1999). Participants were asked on a 7-point Likert scale (range 1-7; from 1 = "I completely disagree" to 7 = "I completely agree") to indicate the extent to which they felt the following while watching the video: bored, frustrated, interested, concerned, excited, angry, scared, nervous, and determined (see analyses on the OSF for detailed results regarding each single affective state; https://osf.io/k2swy). "Bored" served as a manipulation check and "frustrated" to rule out the alternative explanation that frustration (instead of boredom) drove the effects of the present study.

Sadistic affect. To measure sadistic affect, we used three items on a 7-point Likert scale ( $M$ $=1.32, S D=0.97, \alpha=.86$ ): "To be honest, it was a pleasure that I could put the worms into the 
machine"; "I felt satisfaction that I could put the worms into the machine"; and, "It was exciting that I could put the worms into the machine."

Additional measures. To rule out the possibility that disgust or anxiety about the worms interfered with the results, we measured two items on a 7-point Likert scale: "I was disgusted by the worms" $(M=2.76, S D=2.08)$ and, "I was afraid of the worms" $(M=1.56, S D=1.31)$.

\section{Results and Discussion}

Overall, the vast majority of participants did not shred worms $(n=116,89.9 \%)$. However, 13 participants shredded at least one worm ( 1 worm: $n=6,4.7 \%$; 2 worms: $n=3,2.3 \%$; all 3 worms: $n=4,3.1 \%$ ). This distribution was expected, given the nature of the dependent variable. We dichotomized our dependent variable and used the coding "shredded at least one worm vs. no worm" for all further analyses. All results remain the same when using "continuous" coding instead, when bootstrapping all analyses, and when ordinal regression is used. ${ }^{7}$

Sadistic affect. First, to show that worm killing reflects sadistic behavior (deriving pleasure from inflicting harm upon another individual), we correlated worm killing with sadistic affect: Sadistic affect was correlated with worm killing to a notable extent $(r(127)=.51, p<.001)$, which suggests that we indeed assessed sadistic behavior.

Manipulation check. Next, we tested whether our experimental manipulation increased boredom. Participants in the experimental condition reported higher boredom $(M=5.42, S D=$ 1.62) than participants in the control condition $(M=3.23, S D=1.98)$. This difference was significant, $t(127)=6.91, p<.001$, and reflects a large effect $(d=1.22)$, that is, a very strong manipulation of boredom. To a smaller extent, the manipulation also increased frustration $(d=$ $0.42, t(127)=2.36, p=.020)$, although to a much lesser absolute level (control condition: $M=$ $1.87, S D=1.42$, experimental condition: $M=2.54, S D=1.75)$. In our analyses below, we test

7 This is assuming, of course, that our dependent variable is ordinal: In the case of worm killing we have 4 categories indicating when $0,1,2$, or 3 worms are killed. 
whether boredom or frustration (or any of the other affective states) was primarily driving worm killing. Only boredom turned out to be a significant predictor, ruling out alternative explanations.

Main findings. Next, we tested whether people were more likely to shred worms in the experimentally induced boredom condition. Whereas only one person shredded worms in the control condition (1.6\%), twelve did so in the experimental condition (17.9\%). This difference was significant, $\chi^{2}(1, N=129)=9.44, p=.002$, and reflects a large effect size (odds ratio of 13.31). One alternative explanation is that people shredded worms not because of sadism, but out of disgust or anxiety. However, additional analyses revealed that shredding worms does indeed reflect sadism: Sadistic affect was positively correlated with worm shredding $(r(127)=.51, p<$ $.001)$, whereas anxiety $(r(127)=.03, p=.766)$ and disgust $(r(127)=-.12, p=.176)$ towards the worms were not significantly correlated.

Further analyses revealed that boredom, not frustration, is driving worm killing. Boredom was significantly correlated with worm killing $(r(127)=.29, p=.001)$, whereas frustration was not $(r=.13, p=.143)$. When worm killing was regressed simultaneously on boredom and frustration, boredom remained a significant predictor of killing worms $(B=.63, S E=.24, p<$ $.006)$ while frustration $\operatorname{did} \operatorname{not}(B=-.05, S E=.18, p=.790)$.

Overall, the results of Study 6 support the idea that boredom is not only associated with sadism; boredom causes sadism. We found that experimentally induced state boredom increased the likelihood of shredding worms for pleasure. We want to acknowledge, however, that our measures of sadistic affect and state boredom were developed for the present study and not previously validated (although the bug-killing paradigm has been validated in prior research; Buckels et al., 2013).

While Studies 1 through 5 examined self-reported sadism, in this study we relied on a behavioral measure of actual sadistic behavior, namely killing other living creatures for pleasure. In this way, we document that boredom can motivate actual sadistic behavior, in a causal 
analytical test of the relationship between boredom and sadism. In the next study, we test whether this effect generalizes to other paradigms and examine the moderating role of sadistic predispositions (i.e., trait sadism).

\section{Study 7: Joy of destruction vs. creation}

Our primary aim in Study 7 was to conceptually replicate the basic finding that boredom motivates sadism using a different behavioral paradigm. In this study, rather than shredding worms, people were given the opportunity to destroy the income of another participant. Doing so allowed us to answer two additional questions: Does boredom promote sadistic behavior in particular for those already prone to sadism? And, does providing a non-sadistic behavioral alternative alter this relationship? First, to date it remains unclear whether boredom causes sadism primarily among those who are already prone to sadism (i.e., individuals high in trait sadism). Accordingly, in Study 7, we measured individual differences in trait sadism, in addition to our behavioral outcome measure. Second, to date we do not know if boredom persists in causing sadistic behavior when alternative behavioral options are available. In the previous Study 6, individuals' only choice was that of engaging in sadistic behavior vs. refraining from doing so. The question remains whether individuals would still engage in sadistic behavior if given an alternative behavioral option. We implemented this idea in Study 7: Instead of destroying another participant's income, participants could alternatively choose to create income for another participant. Participants had to decide which of the two options they wanted: to create wealth for another person (prosocial) or to destroy it (sadistic). They were also given the option to choose neither.

\section{Methods}

Procedure and participants. In order to achieve high statistical power to detect a potential interaction effect between boredom and trait sadism, the study was conducted online. We used a sample from the U.S., obtained via Amazon Mechanical Turk. We obtained full responses from 
634 individuals $\left(M_{\mathrm{age}}=31.3, S D_{\mathrm{age}}=9.4,50.5 \%\right.$ women $)$, who received $\$ 1$ for participation, and who were randomly assigned to one of two experimental conditions. With this sample size, we were able to detect even small effects $\left(\Delta R^{2}=.02\right)$ with very high statistical power $(.94)$, using an alpha level of $=.05$, two-tailed.

Participants first worked on items assessing trait sadism, and then on three filler items assessing sleep quality. Next, they read instructions about the "joy of destruction game" (see below; the term "joy of destruction game" was not used in the instructions). Afterwards, boredom was induced via random assignment to a video condition. While watching the video, individuals could engage in either destructive behavior or in prosocial behavior (or neither). Finally, we assessed sadistic affect and state boredom.

Trait sadism. As in previous studies, we used the Comprehensive Assessment of Sadistic Tendencies scale (CAST; Buckels \& Paulhus, 2014; Buckels, 2018) to assess trait sadism (range $1-5, M=1.84, S D=0.71, \alpha=.89$; from $1=$ "I completely disagree" to $5=$ "I completely agree").

Joy of destruction game. We used an adapted version of the joy of destruction game (Abbink \& Sadrieh, 2009; Zhang \& Ortmann, 2013) to assess sadistic behavior while bored. Participants could either reduce another person's payment or increase another person's payment. Participants learned that "While watching the video, you will also make a choice about reducing or increasing another person's payment. This other person is a real worker from MTurk you are randomly paired with. We assure you that there is no deception involved in this study. We have given the other person 50 cents as an additional payment. If you want, you can reduce or increase the other person's payment in increments of 10 cents. That is, you can reduce the other person's payment by 10 cents, 20 cents, 30 cents, 40 cents, 50 cents, OR you can increase the other person's payment by 10 cents, 20 cents, 30 cents, 40 cents, or 50 cents. There are no financial costs for you if you choose to reduce or increase the other person's payment. In order to reduce or increase the other person's payment, select the radio buttons in the column that corresponds to 
your choice. Each radio button equates to 10 cents. If you want to reduce the other person's payment, select the column on the left. If you want to increase the other person's payment, select the column on the right. You may select as many radio buttons as you like in either column." A column containing five empty radio buttons with the header "-10" was presented along with a column containing five empty radio buttons with the header "+10."

Then four examples were presented: (a) a 30-cent reduction; (b) a 30-cent creation; (c) neither a reduction nor a creation; and, (d) an invalid response where radio buttons in both columns where selected (participants were excluded who selected radio buttons in both columns). After that, participants responded to two questions regarding understanding of the instructions. If they failed to answer the questions correctly, they were immediately excluded from the study. The full instructions of the game and the two questions can be found on the OSF (https://osf.io/k2swy). ${ }^{8}$

For the analyses, we created two central dependent variables: (1) Destructive behavior: Participants received a " 0 " on this variable if they did not select a radio button at all or created income for the other person; participants received a value above zero (between 10 and 50) if they chose to reduce the income of the other player; (2) Prosocial behavior: Participants received a "0" on this variable if they did not select a radio button at all or destroyed income of the other person; participants received a value above zero (between 10 and 50) if they chose to increase the income of the other person. We chose to create two variables instead of one continuous (ranging from -50 to +50$)$ to disentangle the effects of increased destructiveness from reduced prosocial behavior.

Boredom. Similar to Study 6, we again used an online manipulation of boredom where participants could engage in sadistic behavior while being bored. Specifically, participants in the boredom condition $(n=299)$ watched a 5-minute video of stone. Nothing happened in this video. In the control condition $(n=335)$, participants watched a 5-minute video of two magicians

\footnotetext{
${ }^{8}$ To avoid deception, participants in the present study were matched to participants in other studies who received a bonus payment minus the destruction made by the matched participant from the joy of destruction game. This procedure also holds for Studies 8 and 9.
} 
performing two magic tricks. The videos started automatically, ended automatically, and participants could not stop the video.

An ever-present danger in online boredom studies is the possibility that the boredom induction may work too well, resulting in differential attrition by condition. We used several techniques to avoid higher drop-out rates in the boredom relative to the control condition (this feature is unique to the present study and has not been applied in other experimental online research on boredom). First, participants were asked to participate only if willing to watch a potentially non-interesting video. Second, they read that while watching the video "it is important for the study that you do not do something else. It is important that you pay attention to the video material for the entire 5 minutes. We pay you for paying attention to the video material and not for doing something else. Please understand that we implemented attention checks during the video material so that we can be sure that you really pay attention to the video material. For this purpose, the video will sometimes stop automatically. Then you have 5 seconds to tick a box like this: [box presented]. If you do not tick the box within 5 seconds you will be immediately excluded from the study." Then participants were given an example of what the box and the 5-second time frame looked like. Third, participants had to confirm, "I promise to pay attention to the video material." Fourth, all participants began by watching the video about the stone; after watching the stone for 15 seconds, an attention check occurred and participants had 5 seconds to confirm they were paying attention. Only after this procedure did randomization to the experimental conditions take place. In this way, we likely reduced unsystematic drop-out rates across the conditions $(17.85 \%$ who were assigned to the boredom condition did not finish the study, $10.19 \%$ in the control condition). For instance, gender was not significantly unevenly distributed across conditions, $\chi^{2}(1$, $N=629)=1.40, p=.236$, and neither was trait sadism, $t(632)=0.69, p=.489$. After watching the videos, we implemented another 5-second attention check. As a final quality check, we asked 
participants to report what they had eaten the previous day for lunch. Participants who did not provide a meaningful answer were excluded from the analyses.

Sadistic affect. After the video, sadistic affect was measured by three items (range 1-5, $M=$ $1.30, S D=0.84, \alpha=.97$; from $1=$ "I completely disagree" to $5=$ "I completely agree"): "To be honest, it was a pleasure to reduce the other person's payoff"; "I felt satisfaction to reduce the other person's payoff"; and, "It was exciting to reduce the other person's payoff." To ensure the items applied equally to participants who chose not to take the opportunity to dock another's pay, the instructions above the items stated: "The statements refer to the opportunity to reduce the other person's payoff."

State boredom. To test whether the conditions differed in state boredom, we assessed boredom experience while watching the videos using the 10-item state boredom measure from Van Tilburg and Igou (2012; "During the video, I felt like doing something completely different" and, "... I felt that I did not know what to do with my time"; $\alpha=.87)$. We used this state boredom measure as a manipulation check.

\section{Results and Discussion}

The majority of participants did not destroy the other person's payment ( $n=584,92.1 \%)$. However, 50 participants reduced payment by at least 10 cents ( 10 cents: $n=13,2.1 \%$; 20 cents: $n$ $=5,0.8 \% ; 30$ cents: $n=14,2.2 \% ; 40$ cents: $n=3,0.5 \% ; 50$ cents: $n=15,2.4 \%)$. Again, given the nature of the dependent variable, this distribution was expected. In contrast, the majority of participants $(n=565,89.1 \%)$ exhibited prosocial behavior and added at least 10 cents for the other person ( 10 cents: $n=34,5.4 \% ; 20$ cents: $n=26,4.1 \%$; 30 cents: $n=48,7.6 \%$; 40 cents: $n=12$, 1.9\%; 50 cents: $n=445,70.2 \%$ ). Because of the distribution of our main dependent variable, we also ran all analyses using ordinal regression. We further bootstrapped all analyses (using 5000 resamples). We checked for over-influential cases (Cook's distance was below $<.23$ in all analyses), and we tested whether results remained robust when excluding z-standardized residual outliers 
(above $|1.96|$ standard deviations) and when using a base-10 logarithmic transformation of the dependent variable. Results did not differ by analysis strategy. This also applies to Studies 8 and 9 . For simplicity, we only report the results of the basic linear regression.

Sadistic affect. To show that the destruction of money in the joy of destruction game reflects sadistic behavior, we correlated sadistic affect with destruction of money: Sadistic affect was correlated with destruction of money to a notable extent $(r(632)=.47, p<.001)$, which suggests that we indeed assessed sadistic behavior.

Manipulation check. We tested whether our experimental manipulation increased state boredom. It did; participants in the experimental condition reported higher boredom $(M=3.44, S D$ $=0.96)$ than participants in the control condition $(M=2.41, S D=1.04)$. This difference was significant $(t(632)=13.02, p<.001)$ and reflects a large effect $(d=1.03)$, that is, a very strong manipulation of boredom.

Interestingly, trait sadism significantly $(p<.001)$ moderated the experimental manipulation on state boredom. Specifically, within the control condition, people high in trait sadism (scoring $1 S D$ above the mean) reported significantly higher state boredom (estimated value on state boredom: 2.73 ) than those low in trait sadism (scoring $1 S D$ below the mean; estimated value on state boredom: 2.05). This corresponds to the correlational findings from Study 1, that those high in trait sadism also report higher levels of (chronic) boredom. In contrast, in the experimental (boredom) condition, people low in trait sadism (estimated value: 3.35 ) reported similar high levels of state boredom as those high in trait sadism (estimated value: 3.54 ). That is, while people high in trait sadism were more likely to be bored at baseline (in the control condition), the boredom induction succeeded in inducing similar high levels of boredom across all levels of trait sadism. This pattern also emerged in Studies 8 and 9; these findings are reported on the OSF to avoid redundancy (see https://osf.io/k2swy). 
Main findings. We tested whether inducing boredom led people to destroy other participants' payment. In fact, destruction differed significantly between the experimental conditions. In the control condition (magic tricks video), 5.1\% destroyed at least 10 cents; in the boredom condition (stone video), $11.0 \%$ did so, $\chi^{2}(1, N=634)=7.73, p=.005$. This effect reflects an odds ratio of 2.32 , that is, significantly higher odds for destruction in the boredom condition compared to the control condition. Consistent with this pattern, the overall average amount of payment deducted for all participants in the boredom condition $(M=3.58$ cents, $S D=$ 11.39) was significantly higher than in the control condition $(M=1.34$ cents, $S D=6.72)$, Cohen's $d=0.24, t(632)=3.05, p=.002$.

Turning to prosocial behavior, did boredom likewise increase giving additional money to other participants? It did not; analyses revealed reduced prosocial behavior in the boredom condition $(M=37.59, S D=19.56)$ compared to the control condition $(M=41.16, S D=15.90)$. This difference was significant, Cohen's $d=0.20, t(632)=2.53, p=.012$.

Moderation analyses. Does boredom exacerbate sadistic tendencies in those already prone to sadism? To test whether boredom motivates sadism primarily in those who already had a sadistic predisposition (i.e., individuals high in trait sadism), but not (or less so) in individuals low in trait sadism (i.e., an interaction effect), we regressed payment destruction on trait sadism, experimental conditions, and their interaction. The pattern of results can be found in Figure 2; statistical parameters are presented in Table 5. 


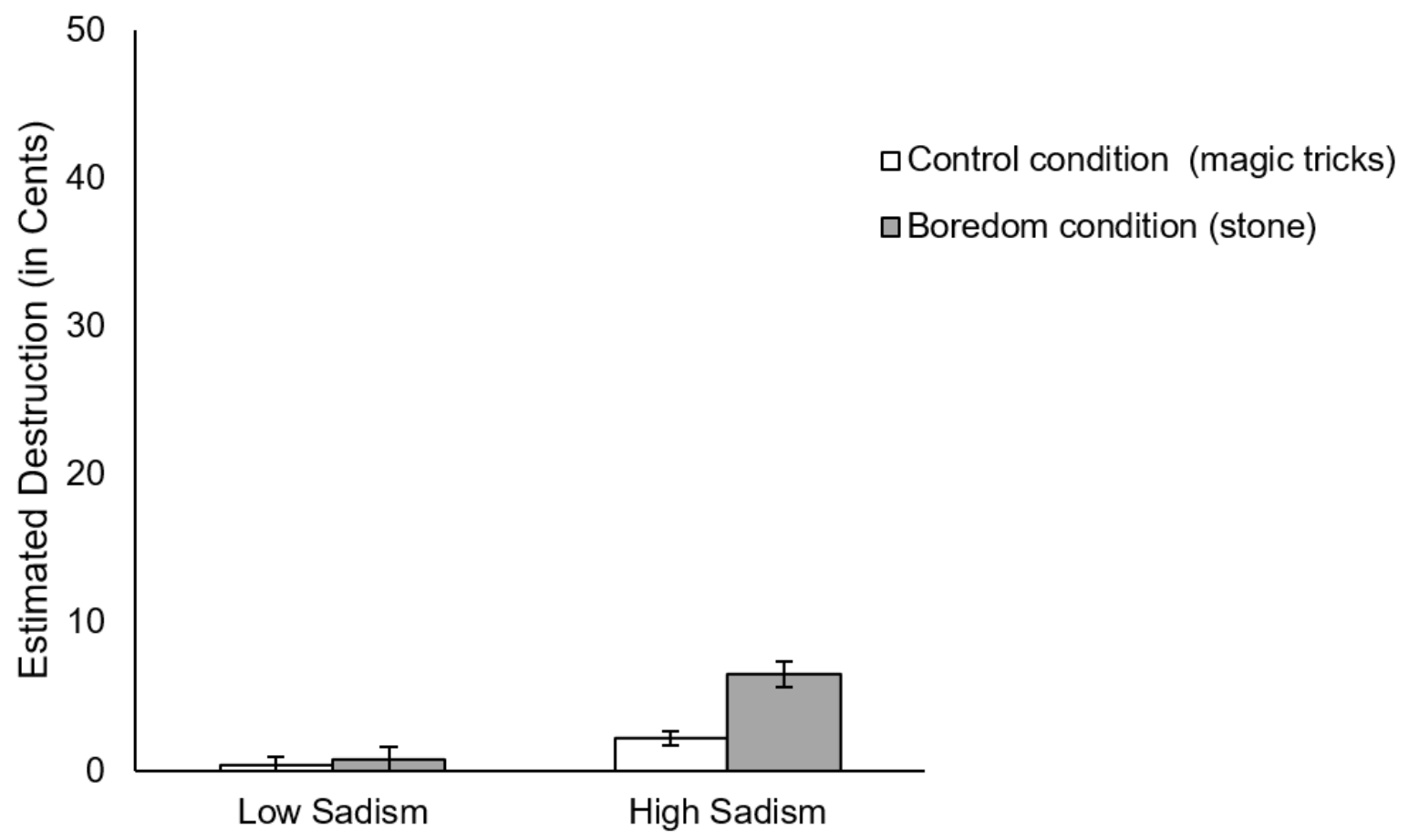

Figure 2. Estimated destruction in cents as a function of trait sadism and the experimental condition in Study $7(N=634)$; low sadism refers to $1 S D$ below the mean of sadism, high sadism refers to $1 S D$ above the mean; error bars reflect standard errors. 
Table 5. Estimated Destruction (in cents) as a function of trait sadism, the condition, and their interaction in Study $7(N=634)$.

\begin{tabular}{lcccccc}
\hline & $B$ & $S E$ & $t$ & $p$ & LLCI & ULCI \\
\hline Constant & 2.49 & 0.36 & 7.01 & $<.001$ & 1.80 & 3.19 \\
Condition & 2.35 & 0.71 & 3.31 & $<.001$ & 0.96 & 3.75 \\
Sadism & 2.97 & 0.50 & 5.88 & $<.001$ & 1.97 & 3.96 \\
Condition $\times$ Sadism & 3.13 & 1.01 & 3.10 & .002 & 1.15 & 5.11 \\
$\begin{array}{l}\text { Conditional effect at low sadism } \\
\text { Condition }\end{array}$ & 0.34 & 0.96 & 0.35 & .721 & -1.54 & 2.23 \\
$\begin{array}{l}\text { Conditional effect at high sadism } \\
\text { Condition }\end{array}$ & & & & & & \\
\hline
\end{tabular}

Note. The boredom condition is coded +0.5 , the control condition is coded -0.5 ; low sadism refers to $1 S D$ below the mean of sadism; high sadism refers to $1 S D$ above the mean; sadism is centered to the mean.

Moderation analyses revealed remarkable findings. First, we found a main effect of trait sadism; people higher in trait sadism were more likely to destroy the other person's payment. Second, we found a main effect of boredom; people destroyed more money in the boredom compared to the control condition. Third, these main effects were, however, qualified by an interaction between boredom and trait sadism. The boredom manipulation particularly increased payment destruction among people predisposed to sadism; it had little to no effect on people who were not predisposed to be sadistic. That is, we found significant support for the idea that boredom motivates sadism only in those individuals already high in trait sadism.

In sum, Study 7 conceptually replicated the causal role of boredom using a different behavioral paradigm - that of destroying other participants' payment. In addition, it revealed that when given a non-sadistic behavioral option as an alternative, only individuals high in trait sadism increased their destructive behavior when bored. In addition, Study 7 suggests that individuals high in trait sadism are not indiscriminate in their choices of what to do when bored. That is, they do not choose just any behavior to counter boredom; they specifically chose a destructive behavior. In contrast, we found no support for boredom as a cause of sadistic behavior among individuals low in trait sadism, at least not when another more positive option was available. In 
the next study, we tested whether this was still the case when we removed that alternative behavioral option.

\section{Study 8: Joy of destruction - No good alternative}

In Study 8, we addressed three important issues. First, we once more aimed to replicate the basic effect that boredom increases sadistic behavior. Second, we wanted to test whether removing the prosocial option would increase payment destruction even among those low in trait sadism. We reasoned that when one has no good alternatives, then even individuals low in trait sadism might engage in destructiveness, because it is the only available option on the table. Third, we addressed the possibility that giving participants a long opportunity to act (i.e., the 5-minute period while watching the video) was in and of itself increasing the likelihood of non-prosocial, sadistic behavior. Therefore, in Study 8, we included an additional control condition in which participants could immediately destroy another person's payment, without experiencing the 5-minute video period.

\section{Methods}

Procedure and participants. The procedure followed exactly that of Study 7 . The only differences were the dependent variable itself and the addition of a measure of state frustration and relaxation. In order to achieve high statistical power to detect a potential interaction effect between boredom and trait sadism, the study was again conducted online. We used a sample from the U.S., obtained via Amazon Mechanical Turk. We obtained full responses from 1332 individuals $\left(M_{\mathrm{age}}=\right.$ $31.0, S D_{\text {age }}=9.5,47.2 \%$ women) who each received $\$ 1$ for participation and who were randomly assigned to one of three experimental conditions. With this sample size, we were able to detect even small effects $\left(\Delta R^{2}=.02\right)$ with very high statistical power (.99), using an alpha level of .05 , two-tailed. 
Trait sadism. As in previous studies, we used the Comprehensive Assessment of Sadistic Tendencies scale (CAST; Buckels \& Paulhus, 2014; Buckels, 2018) to assess trait sadism (range $1-5, M=1.79, S D=0.70, \alpha=.89)$.

Joy of destruction game. In this study, participants could destroy another participant's payment, but they could not create or add to it. As in Study 7, participants could reduce another participant's payment in 10-cent increments (min. 0 cents, max. 50 cents).

Boredom. We used three experimental conditions. As in Studies 6 and 7, we again used an online manipulation of boredom where participants could engage in sadistic behavior while being bored. Participants in the boredom condition $(n=421)$ again watched the 5-minute video of a stone. In the first control condition $(n=469)$, participants again watched the same 5 -minute video of two magicians performing two magic tricks. In addition, we added a second control condition $(n=442)$ in which participants immediately completed the joy of destruction game, without first watching a video. Because participants were asked to decide immediately, they had a shorter opportunity (timewise) to reduce the other participant's payment. In this second control condition, after participants made their decision in the game, they then watched the same video of the stone as those in the boredom condition (in order to induce similar dropout rates across conditions; Zhou \& Fishbach, 2016). The videos started automatically, ended automatically, and participants could not stop the video.

We applied the same attention and quality checks of Study 7 in order to avoid higher dropout rates in the boredom compared to the control conditions $(10.43 \%$ who were assigned to the boredom condition did not finish the study; $7.13 \%$ in the first control condition; $11.07 \%$ in the second control condition). Gender was not significantly unevenly distributed across conditions, $\chi^{2}(2, N=1325)=1.40, p=.496$, and neither was trait sadism, $F(2,1329)=1.24, p=.291$.

Sadistic affect. After the video, sadistic affect was measured by the same three items as in Study $7(M=1.40, S D=0.93, \alpha=.95)$. 
State boredom. We used the same measure as in Study 7 as a manipulation check.

Additional measures. To address the possibility that frustration or relaxation were driving the effects, we added two items: "During the video, I was frustrated" and, "During the video, I was relaxed."

\section{Results and Discussion}

As in Study 7, the majority of participants did not destroy the other person's payment $(n=$ 1010, 75.8\%). However, 322 participants reduced it by at least 10 cents ( 10 cents: $n=112,8.4 \%$; 20 cents: $n=35,2.6 \% ; 30$ cents: $n=26,2.0 \% ; 40$ cents: $n=11,0.8 \% ; 50$ cents: $n=138,10.4 \%$, a much larger percentage than when a prosocial alternative was available (18\% destroying payment in this study vs. $8 \%$ in Study 7 where there was the prosocial alternative). Again, due to the nature of the dependent variable, this distribution was expected.

Sadistic affect. To show that the destruction of money reflects sadistic behavior, we correlated sadistic affect with destruction of money: Sadistic affect was correlated with destruction of money to a notable extent $(r(1330)=.62, p<.001)$ which suggests that we indeed assessed sadistic behavior.

Manipulation check. First, we tested whether our experimental manipulation increased boredom. Participants in the experimental condition reported higher boredom $(M=3.55, S D=$ 0.93 ) than participants in the first control condition ("magic tricks"; $M=2.39, S D=1.05$ ). This difference was significant $(t(888)=17.28, p<.001)$ and reflects a large effect $\left(d=1.17, \eta^{2}=.25\right)$, that is, a very strong manipulation of boredom. We also assessed boredom in the second control condition after watching the stone video; thus, we expected boredom rates in this condition (during the video) to be equivalent to those in the boredom condition. They were; we observed high levels of boredom in the second control condition $(M=3.51, S D=1.10$; pairwise comparison with the boredom condition, $d=0.04, t(861)=0.64, p=.520)$, in which participants watched the 
same video as in the boredom condition, but after the dependent variable; that is, in this condition, participants were bored after the dependent variable (in order to reduce unsystematic drop-outs).

Our manipulation also increased frustration, albeit to a smaller extent $\left(\eta^{2}=.09, F(2,1329)\right.$ $=67.46, p<.001$ ) and on a low absolute level (boredom condition: $M=2.48, S D=1.36$; first control condition: $M=1.59, S D=0.95$; second control condition: $M=2.29, S D=1.29)$. A similar pattern was found for relaxation $\left(\eta^{2}=.06, F(2,1329)=38.89, p<.001\right.$; boredom condition: $M=$ 3.88, $S D=1.06$; first control condition: $M=3.28, S D=1.27$; second control condition: $M=3.29$, $S D=1.20)$. When destruction was regressed simultaneously on boredom, frustration, and relaxation, boredom remained a significant predictor $(B=.1 .95, S E=.60, p=.001)$; frustration also played a significant role $(B=2.80, S E=.58, p<.001)$, while relaxation $\operatorname{did} \operatorname{not}(B=0.83, S E$ $=.55, p=.133)$.

Main findings. As predicted, experimentally inducing boredom increased the likelihood of destroying others' payment: In the first control condition (magic tricks video), $21.7 \%$ reduced payment by at least 10 cents; in the second control condition (no video), 15.4\% did so; and, in the boredom condition (stone video), 36.1\% destroyed another participant's payment (all pairwise comparisons with the boredom condition, $p \mathrm{~s}<.001)$. These differences are also significant when comparing the overall magnitude of monetary payment deducted, $F(2,1329)=28.35, p<.001$. People destroyed significantly more money in the boredom condition $(M=11.85$ cents, $S D=$ 19.22) compared to the first control condition $(M=6.84$ cents, $S D=15.45)$, Cohen's $d=0.29$, $t(888)=4.30, p<.001$, and the second control condition $(M=3.94$ cents, $S D=11.30), d=0.51$, $t(861)=7.42, p<.001$.

Moderation analyses. Previously, we found in Study 7 that trait sadism moderated the effects of boredom on sadistic behavior. That is, boredom only increased sadistic behavior among those predisposed to behave sadistically. Was that still the case when we removed other, more prosocial behavioral alternatives? To find out, we tested whether boredom in this study motivated 
sadism primarily among people predisposed to sadism (i.e., individuals high in trait sadism), but not (or less so) in people low in trait sadism (i.e., an interaction effect) by regressing payment destruction on trait sadism, experimental condition (dummy coded), and their interactions. The pattern of results can be found in Figure 3; statistical parameters are presented in Table 6.

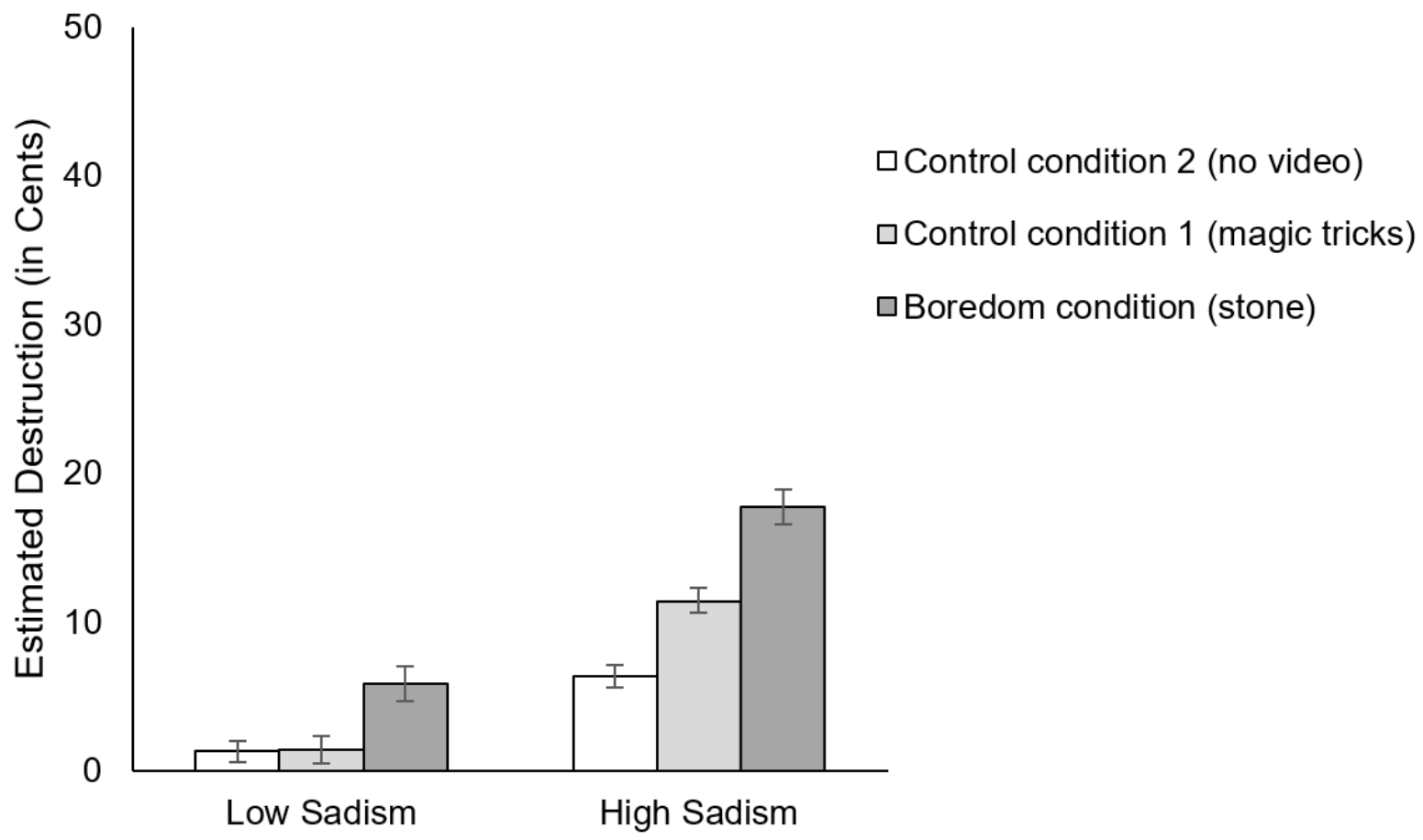

Figure 3. Estimated destruction in cents as a function of trait sadism and the experimental conditions in Study $8(N=1332)$; low sadism refers to $1 S D$ below the mean of sadism, high sadism refers to $1 S D$ above the mean; error bars reflect standard errors. The conditions are sorted in ascending order, that is why control condition 2 comes first. 
Table 6. Estimated Destruction (in cents) as a function of trait sadism, the conditions, and their interactions in Study $8(N=1332)$.

\begin{tabular}{lcccccc}
\hline & $B$ & $S E$ & $t$ & $p$ & $L L C I$ & ULCI \\
\hline Constant & 11.95 & 0.72 & 16.68 & $<.001$ & 10.54 & 13.35 \\
Dummy 1 (Magic vs Bored) & -5.41 & 0.99 & -5.48 & $<.001$ & -7.35 & -3.47 \\
Dummy 2 (No video vs Bored) & -7.89 & 1.00 & -7.88 & $<.001$ & -9.86 & -5.93 \\
Sadism & 9.36 & 1.02 & 9.19 & $<.001$ & 7.37 & 11.36 \\
Dummy 1 $\times$ Sadism & -1.44 & 1.37 & -1.05 & .292 & -4.13 & 1.24 \\
Dummy 2 $\times$ Sadism & -5.62 & 1.51 & -3.73 & $<.001$ & -8.57 & -2.67 \\
Conditional effects at low sadism & & & & & & \\
Dummy 1 (Magic vs Bored) & -4.46 & 1.34 & -3.33 & $<.001$ & -7.10 & -1.84 \\
Dummy 2 (No video vs Bored) & -4.22 & 1.38 & -3.07 & .002 & -6.93 & -1.53 \\
Conditional effects at high sadism & & & & & & \\
Dummy 1 (Magic vs Bored) & -6.30 & 1.28 & -4.89 & $<.001$ & -8.81 & -3.77 \\
Dummy 2 (No video vs Bored) & -11.34 & 1.39 & -8.19 & $<.001$ & -14.06 & -8.63 \\
\hline
\end{tabular}

Note. The boredom condition is the reference group in dummy coding system; Dummy 1 ( 1 = first control condition [magic tricks], $0=$ otherwise), Dummy $2(1=$ second control condition [no video], $0=$ otherwise). Low sadism refers to $1 \mathrm{SD}$ below the mean of sadism, high sadism refers to $1 \mathrm{SD}$ above the mean.

The results revealed four remarkable findings. First, as we suspected, giving individuals a longer opportunity for destruction (a 5-minute video period vs. deciding immediately) increased overall destruction, especially in individuals high in trait sadism. Second, we found a main effect of trait sadism, such that individuals higher in trait sadism destroyed more. Third, we observed a main effect of boredom, such that individuals in the boredom condition destroyed more money compared to the control conditions. Fourth, this main effect was, however, not qualified by an interaction between boredom and trait sadism. That is, unlike in Study 7, we found that boredom increased destruction in individuals both high and low in trait sadism. Remarkably, this was the case even when looking at the very bottom of the sadism scale (i.e., individuals scoring on average of 1.00 on the 1 to 5 sadism scale). In sum, moderation analyses revealed that (a) opportunity increased destruction, especially among individuals high in trait sadism; (b) trait sadism itself increased the likelihood that an individual would destroy another's payment; and, (c) boredom 
increased destruction in individuals both high and low in trait sadism when there was no other good alternative behavioral option available.

\section{Study 9: Joy of destruction and third-party punishment}

We had three main aims in running Study 9. First, we aimed to replicate the findings of Study 8 in a pre-registered experiment with high statistical power. Second, up to this point, we have remained empirically silent regarding the psychological processes underlying the link between boredom and sadism. As such, in this study, we explored why boredom promotes sadism, and we address the question via mediation. In the theoretical part of this paper, we have argued that sadism can result from boredom stemming from attention deficits because sadistic behavior can provide exciting experiences and increased pursuit of novel experiences. Accordingly, we examined whether boredom elicits the attention-related mechanisms of seeking out exciting experiences and seeking out novel experiences. Then we tested whether these states foster sadistic behavior. We have further argued that sadism can reflect a "tool" to avoid feeling meaninglessness. Accordingly, we examined whether boredom elicits the mechanism of meaning seeking and tested whether meaning seeking fosters sadistic behavior. Overall, we tested whether boredom leads to excitement seeking, novelty seeking, and meaning seeking and whether these in turn relate to sadistic affect, which in turn relates to the destruction of money (see Figure 4).

Third, correlational research in our earlier studies suggests that boredom may be related not only to sadism, but to aggression more generally. Thus, we tested whether boredom not only promotes sadistic (proactive) aggression, but also other forms of aggression. Specifically, we tested whether boredom promotes reactive aggression in a classic third-party punishment paradigm (Fehr \& Fischbacher, 2004). In the third-party punishment paradigm, participants are confronted with an individual who has previously behaved unfairly (i.e., a provocation). Participants then have the opportunity to destroy that unfair individual's income. Overall, Study 9 
used a 2 (control condition vs. boredom condition) $\times 2$ (joy of destruction game vs. third-party punishment paradigm) between-subjects design.

\section{Methods}

Procedure and participants. Study 9 materials, sample size (2000 participants), exclusion criteria, hypotheses, and data analysis were pre-registered on aspredicted.org. The pre-registration is accessible on the OSF (see https://osf.io/k2swy). All reported analyses follow the preregistration. We obtained full responses from $N=2002$ individuals on Amazon Mechanical Turk $\left(M_{\text {age }}=31.6, S D_{\text {age }}=12.5,50.8 \%\right.$ women $)$ who each received $\$ 1.50$ for participation. The procedure exactly replicated that of Study 8 .

Trait sadism. As in previous studies, we used the Comprehensive Assessment of Sadistic Tendencies scale (CAST; Buckels \& Paulhus, 2014; Buckels, 2018) to assess trait sadism.

Joy of destruction game vs. third-party punishment paradigm. Participants were randomly assigned to the joy of destruction game $(n=1019)$ or to the third-party punishment paradigm $(n=$ 983). The joy of destruction game was exactly the same as in Study 8: Participants could reduce another participant's payment in 10-cent increments (min. 0 cents, max. 50 cents).

In the third-party punishment paradigm (see Pfattheicher, Sassenrath, \& Keller, 2019, for the same procedure), participants were told that "Your job is to judge a decision made by Person A. Person A has participated in a decision-making game including money. In this game, Person A has been randomly paired with another real person (called 'Person B' in the following). We gave Person A 100 cents as endowment. Person B, in contrast, received 0 cents (i.e., nothing). Person A had to determine how to split the 100 cents between him/herself and Person B."

Next, participants were told that Person A took 70 cents while giving Person B 30 cents, thus distributing the 100 cents in an unfair way. Player B had no choice but to accept the decision of Player A. As such, participants observe an unjust distribution of money (Eriksson et al., 2017; 
Nelissen \& Zeelenberg, 2009). Participants were then given the option to reduce Person A's payment in 10 -cent increments (min. 0 cents, max. 50 cents). ${ }^{9}$

Thus, in both the joy of destruction game as well as in the third-party punishment paradigm, participants could harm another participant financially without any consequence for their own payment. The difference between the two games is that in the third-party punishment paradigm, participants were potentially reacting to a moral provocation (i.e., the unfair distribution of money), whereas in the joy of destruction game there was no such provocation.

Boredom. We used the same experimental conditions as in Study 8: Participants in the boredom condition $(n=945)$ watched a 5-minute video of a stone. In the control condition $(n=$ 1057), participants watched a 5-minute video of two magicians performing magic tricks. We applied the same attention and quality checks of Study 7 and 8 - this time pre-registered - in order to avoid higher drop-out rates in the boredom compared to the control conditions $(13.86 \%$ who were assigned to the boredom condition did not finish the study; $11.10 \%$ in the control condition). Gender and trait sadism were evenly distributed across conditions, $\chi^{2}(1, N=1993)=0.45, p=$ $.831 ; F(1,2000)=1.21, p=.144$.

Sadistic affect. After the video, sadistic affect was measured by the same three items as in Studies 7 and 8 (range $1-5 ; M=1.82, S D=1.15, \alpha=.94$; from $1=$ "I completely disagree" to $5=$ “I completely agree”).

Mediators. We pre-registered three mediators, each assessed with two items. Excitement seeking (range $1-5 ; M=3.15, S D=1.40, \alpha=.90$; from $1=$ "I completely disagree" to $5=$ "I completely agree") was measured with two items: "During the video, I wanted to change to more exciting behaviors" and, "During the video, I felt like doing something more exciting." Novelty seeking $(M=2.82, S D=1.27, \alpha=.89)$ was measured with the two items, "During the video, I was up to try out something novel" and, "During the video, I wanted to try out something new." Need

\footnotetext{
${ }^{9}$ To avoid deception, participants in the third-party punishment paradigm were matched to dyads of participants from another study in which another participant has decided for a 70:30 split (instead of a fair 50:50 split).
} 
for meaning $(M=3.17, S D=1.38, \alpha=.87)$ was measured with the two items, "During the video, I wanted to turn to a more meaningful activity" and, "During the video, I felt like doing something purposeful."

State boredom. State boredom was assessed with the item, "During the video, I was bored." This item served at the manipulation check (as pre-registered).

Additional measures. To address the possibility that frustration or relaxation were driving the effects, we added two items: "During the video, I was frustrated" and, "During the video, I was relaxed."

\section{Results}

Overall, the majority of participants did not destroy the other person's payment ( $n=659$, $64.7 \%$ ) in the joy of destruction game, as in Study 8 . However, $35.3 \%$ (or 360 participants) chose to dock the other person's pay by at least 10 cents ( 10 cents: $n=85,8.3 \% ; 20$ cents: $n=37,3.6 \%$; 30 cents: $n=35,3.4 \%$; 40 cents: $n=19,1.9 \% ; 50$ cents: $n=184,18.1 \%$ ); this distribution followed the distribution of Study 8 .

In the third-party punishment paradigm, by comparison, a minority of participants did not destroy the other person's payment $(n=287,29.2 \%)$. This is in line with previous research on the third-party punishment paradigm, showing that a majority punish unfair other individuals (e.g., Pfattheicher, Sassenrath, \& Keller, 2019). Over seventy percent (or 696 participants) reduced the person's pay by at least 10 cents (10 cents: $n=121,12.3 \%$; 20 cents: $n=257,26.1 \%$; 30 cents: $n$ $=77,7.8 \%$; 40 cents: $n=39,4.0 \% ; 50$ cents: $n=202,20.5 \%)$. In fact, participants reduced more money in the third-party punishment paradigm $(M=20.67, S D=18.27)$ than in the joy of destruction game $(M=12.37, S D=19.56), d=0.44, t(2000)=9.79, p<.001$.

Sadistic affect. To show that the destruction of money in the joy of destruction game reflects sadistic behavior, we correlated sadistic affect with destruction of money: Sadistic affect 
was correlated with destruction of money to a notable extent $(r(1017)=.63, p<.001)$, which suggests that we indeed assessed sadistic behavior.

Sadistic affect and destruction were also correlated in the third-party punishment paradigm, $r(981)=.40, p<.001$, although to a significantly $(p<.001)$ lesser extent. This suggests that punishing an unfair individual falls in line with positive affect (cf. de Quervain et al., 2004) and has a sadistic component (inflicting harm on another individual and deriving pleasure from it). The lower correlation compared to the joy of destruction game suggests that there are additional factors (beyond sadistic affect) promoting destruction in the third-party punishment paradigm; one likely candidate is anger towards the unfair individual (Nelissen et al., 2009).

Manipulation check. First, we tested whether our experimental manipulation increased state boredom. Participants in the experimental (boredom) condition reported higher boredom ( $M$ $=4.16, S D=1.15)$ than participants in the control condition $(M=2.19, S D=1.31)$. This difference was significant $(t(2000)=35.62, p<.001)$ and reflects a large effect $(d=1.60)$, that is, a very strong manipulation of boredom.

Main findings. As predicted, we replicated Study 8: In the joy of destruction game, inducing boredom increased the likelihood of destroying others' payment. In the control (magic tricks video) condition, $30.9 \%$ reduced payment by at least 10 cents; in the boredom (stone video) condition, $40.3 \%$ destroyed another participant's payment $\left(\chi^{2}(1, N=1019)=9.80, p=.002\right)$. This difference also occurred when comparing the overall magnitude of monetary payment destroyed. People destroyed significantly more money in the boredom condition $(M=14.60$ cents, $S D=$ $20.85)$ than in the control condition $(M=10.41$ cents, $S D=18.15), d=0.21, t(1017)=3.44, p=$ .001 .

In the third-party punishment paradigm, inducing boredom also increased the likelihood of destroying others' payment. In the control condition, $65.6 \%$ reduced payment by at least 10 cents; in the boredom condition, $76.5 \%$ destroyed another participant's payment $\left(\chi^{2}(1, N=983)=14.31\right.$, 
$p<.001)$. This difference also occurred when comparing the overall magnitude of monetary payment deducted. People docked significantly more money in the boredom condition $(M=23.43$ cents, $S D=18.87)$ than in the control condition $(M=18.15$ cents, $S D=17.55), d=0.29, t(981)=$ $4.55, p<.001$. Overall, in both paradigms, we found that boredom increased destruction of money (i.e., a main effect of boredom). This effect was not significantly moderated by the paradigm: the interaction between boredom (boredom vs. control condition) and the paradigm (joy of destruction game vs. third-party punishment paradigm) turned out to be non-significant, $F(1,1998)=0.41, p$ $=.520$. That is, the main effect of boredom occurred to a similar extent in both paradigms. Moderation analyses. In the moderation analyses, we tested whether trait sadism moderates the effects reported above. We present the moderation analyses separately for the joy of destruction game and for the third-party punishment paradigm (as pre-registered). Presenting the results in this way allows us to see whether the findings obtained in Study 8 (in the joy of destruction game) replicate in each of the paradigms in Study 9 (in the joy of destruction game and in the third-party punishment). Please note that in Study 9, the three-way interaction between trait sadism $\times$ boredom (control condition vs. boredom condition) $\times$ paradigm $($ joy of destruction game vs. third-party punishment paradigm) was not significant $(p=.157)$

Details of the moderation analyses — separated by the two paradigms — are presented in Table 7. The results revealed four remarkable findings. First, we found a main effect of trait sadism in both paradigms (joy of destruction game and third-party punishment paradigm), such that individuals higher in trait sadism destroyed more money. Second, we found a main effect of boredom in both paradigms, such that individuals in the boredom condition destroyed more money compared to the control condition. Third, in the joy of destruction game, this main effect was, however, not qualified by an interaction between boredom and trait sadism, replicating Study 8 . Fourth, in the third-party punishment paradigm, the main effect of boredom was qualified by an interaction between boredom and trait sadism. Specifically, for those scoring relatively high on 
trait sadism, boredom did significantly increase monetary deduction, whereas for those scoring relatively low on trait sadism, boredom did not significantly increase monetary deductions. Please note, however, that the effects of boredom persist even at quite low levels of sadism: the effect of boredom condition on monetary destruction only became non-significant $(p>.05)$ at trait sadism scores below 1.17 (possible range 1-5), that is, when trait sadism is practically non-existent. Thus, we should expect effects of boredom in most individuals, as the effects remains present at even very low values of trait sadism. We discuss these findings below.

Table 7. Estimated destruction (in cents) as a function of trait sadism, the conditions, and their interactions in Study $9(N=2002)$.

\begin{tabular}{lcccccc}
\hline & $B$ & $S E$ & $t$ & $p$ & $L L C I$ & ULCI \\
\hline Joy of destruction game & & & & & & \\
Constant & 12.20 & 0.55 & 22.05 & $<.001$ & 11.12 & 13.29 \\
Condition & 4.67 & 1.11 & 4.22 & $<.001$ & 2.50 & 6.84 \\
Sadism & 9.50 & 0.63 & 15.06 & $<.001$ & 8.26 & 10.74 \\
Condition $\times$ Sadism & 1.36 & 1.26 & 1.08 & .281 & -1.11 & 3.83 \\
Conditional effect at low sadism & & & & & & \\
Condition & 3.51 & 1.57 & 2.23 & .026 & 0.42 & 6.59 \\
$\begin{array}{l}\text { Conditional effect at high sadism } \\
\text { Condition }\end{array}$ & 5.83 & 1.52 & 3.85 & $<.001$ & 2.86 & 8.81 \\
& & & & & & \\
Third-party punishment paradigm & & & & & & \\
Constant & 21.08 & 0.56 & 37.72 & $<.001$ & 19.98 & 22.18 \\
Condition & 5.77 & 1.12 & 5.17 & $<.001$ & 3.58 & 7.97 \\
Sadism & 6.13 & 0.68 & 9.02 & $<.001$ & 4.80 & 7.46 \\
Condition $\times$ Sadism & 3.99 & 1.36 & 2.93 & .003 & 1.32 & 6.65 \\
$\begin{array}{l}\text { Conditional effect at low sadism } \\
\text { Condition }\end{array}$ & 2.37 & 1.57 & 1.51 & .31 & -0.71 & 5.45 \\
$\begin{array}{l}\text { Conditional effect at high sadism } \\
\text { Condition }\end{array}$ & 9.18 & 1.65 & 5.56 & $<.001$ & 5.94 & 12.42 \\
\hline
\end{tabular}

Note. The boredom condition is coded +0.5 , the control condition is coded -0.5 ; low sadism refers to $1 \mathrm{SD}$ below the mean of sadism, high sadism refers to $1 \mathrm{SD}$ above the mean; sadism is centered to the mean 
Indirect effect analyses. As pre-registered, we conducted indirect effect analyses separately for the two paradigms. We report the results for the joy of destruction game first. Using Process Model 80 (Hayes, 2018), we tested whether the experimental condition (boredom vs. control) leads to excitement seeking, novelty seeking, and need for meaning; which in turn predict sadistic affect, which in turn predicts destruction of money (see Figure 4). Results revealed a significant indirect effect for excitement seeking via sadistic affect on monetary destruction; the $95 \%$ bootstrapped CI of the indirect effect excluded zero [1.390; 3.917]. We also found a significant indirect effect for novelty seeking via sadistic affect on monetary destruction (95\% CI indirect effect $[0.823 ; 1.887])$. In contrast, we did not find a significant indirect effect for need for meaning directly on monetary destruction $(95 \% \mathrm{CI}$ indirect effect $[-0.876 ; 2.456])$, whereas we found a significant negative indirect effect via sadistic affect (95\% CI indirect effect [-2.394; -0.332$])$, suggesting that need for meaning functions as a suppressor rather than a mediator (i.e., the effect of the experimental boredom condition on destruction increases rather than decreases when need for meaning was controlled for; see OSF for corresponding analyses).

We additionally checked the impact of frustration on these indirect effect analyses. Although frustration had an effect on monetary destruction when controlling for the other mediators, the indirect effects of excitement seeking and novelty seeking remained significant when frustration was controlled for (see OSF for these analyses, https://osf.io/k2swy). Overall, indirect effect analyses suggest that excitement seeking and novelty seeking, but not need for meaning, mediated the effect of the experimental condition on sadistic behavior. 


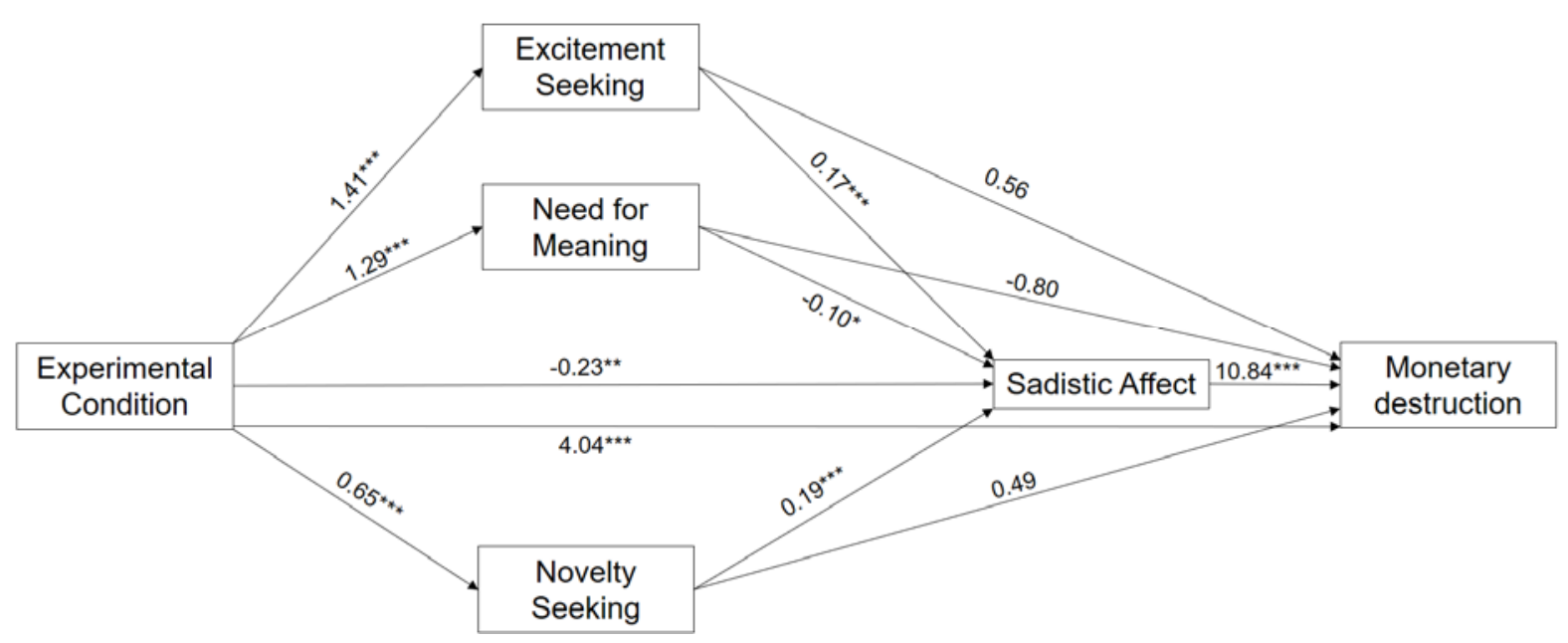

Figure 4. Indirect effect analysis (Process Model 80; Hayes, 2018) predicting monetary destruction in the joy of destruction game $(N=1019)$; experimental condition: control condition $=$ 0 , boredom condition $=1$; unstandardized beta-coefficients are reported; $* p<.05, * * p<.01, * * *$ $p<.001$

The pattern of results in the third-party punishment was the same as in the joy of destruction game (see OSF for the statistical parameters of each path, https://osf.io/k2swy). Results revealed a significant indirect effect for excitement seeking via sadistic affect on monetary destruction; the $95 \%$ bootstrapped CI of the indirect effect excluded zero $[0.512 ; 2.020]$. We also found a significant indirect effect for novelty seeking via sadistic affect on monetary destruction (95\% CI indirect effect $[0.313 ; 0.914])$. In contrast, we did not find a significant indirect effect for need for meaning, either directly on monetary destruction $(95 \% \mathrm{CI}$ indirect effect $[-1.887 ; 1.071])$ or via sadistic affect $(95 \% \mathrm{CI}$ indirect effect $[-0.801 ; 0.431])$. The indirect effects of excitement seeking and novelty seeking remained significant when frustration was controlled for (see OSF for these analyses, https://osf.io/k2swy). Thus, as in the joy of destruction game, the effect of the experimental boredom condition was driven by excitement seeking and novelty seeking, but not need for meaning. 


\section{Discussion}

Study 9 provides important insights into the relation between boredom and sadism. First, we replicated the basic effect that boredom increases sadistic behavior in a well-powered and preregistered study. Second, we replicated the effect of Study 8 that, when no behavioral alternatives are present, boredom promotes sadism in individuals both low and high in trait sadism. Third, we showed why boredom leads to sadism: Namely, excitement seeking and novelty seeking, but not need for meaning, mediated the effect of boredom on sadistic behavior. Fourth, we show that boredom not only promotes sadistic (proactive) aggression, but that it also promotes reactive aggression in the third-party punishment paradigm. Previously, in Study 5B, we showed that trait boredom was positively correlated with the reactive aggressive fantasy of 'paying back someone who has hurt you.' Study 9 adds causal evidence. Thus, we can conclude that effects of boredom generalize to other forms of aggression as well.

Fifth, we want to acknowledge a potential limitation and post-hoc alternative interpretation of these results, namely that although we show that boredom promotes reactive aggressive behavior, we cannot necessarily conclude from the pattern of results that boredom actively promotes reactive aggression as a motive (i.e., the motive to harm an individual who has previously behaved unfairly). It is alternatively also possible that individuals destroy payment for the same motives (e.g., excitement seeking) in both the joy of destruction game and the third-party punishment paradigm; that is, people in the third-party punishment paradigm might have destroyed payment because they wanted to punish the wrong-doer, or they might have destroyed payments because of (sadistic) excitement while they could use the wrong-doers' actions as a cover or excuse. However, since we have not measured reactive aggression as a motive and instead have only observed the behavioral outcome, the present research remains silent about whether boredom promotes reactive aggression as a motive. We want to note, however, that these are post-hoc considerations raised only after the results of the study were known. 
Finally, we do find that trait sadism is a moderator in the third-party punishment paradigm; the effect of boredom on destruction is particularly pronounced in those high in trait sadism. We speculate that the boredom-induced motivation of destruction accounts for the similar effect in the third-party punishment paradigm and the joy of destruction game for those high in trait sadism. In contrast, those very low in trait sadism already destroy to a substantial degree in the third-party punishment paradigm, likely in the name of justice (Nelissen \& Zeelenberg, 2009). Destroying too much money (e.g., more than 20 cents), however, would be unjust again; thus, for those people, boredom cannot further increase the motivation to destroy. This is, however, post hoc speculation that needs further empirical investigation.

\section{General Discussion}

"Boredom is the root of all evil," stated Danish philosopher Søren Kierkegaard (p.267, 1843/2009). The present contribution shows that boredom does indeed motivate people to harm other individuals and to experience pleasure (i.e., sadistic aggression). In testing the idea that boredom motivates sadism, we have applied three different perspectives: a personality perspective, a societal perspective, and an experimental perspective. Using a personality perspective, we

addressed the question of whether sadistic tendencies are more likely among people who are prone to experiencing chronic boredom in everyday life. Indeed, we found that trait sadism was robustly associated with boredom proneness, even after controlling for two well-established personality models (the Big Five and the HEXACO).

Taking a societal perspective, we documented that the relationship between boredom and sadism generalizes across a variety of highly relevant, and important, societal contexts. We showed that boredom proneness in everyday life predicts harming others for fun on the internet (online trolling). We also documented the relationship between boredom and sadism in the military. Specifically, we showed that sadistic tendencies towards one's fellow soldiers were more common among people who experienced greater boredom during their time in the military. The 
relationship between boredom and sadism even emerged in the context of child care. Parents' sadistic tendencies towards their own children were greater when they reported higher levels of boredom while caring for their own children. In our final contextual study, we showed that boredom proneness in everyday life positively predicts the sadistic fantasy of shooting somebody for fun. Overall, this societal perspective highlights several important contexts where boredom might motivate sadism and suggests that this relationship generalizes across many situations.

Finally, we adopted an experimental perspective and showed that this relationship is not merely correlational; across four experimental studies totaling over 4000 participants, we found robust evidence that boredom does in fact cause sadistic behavior. Specifically, we document that inducing boredom increased the likelihood that people would shred worms or destroy another individual's income for pleasure. Furthermore, what people choose to do depends on the options available to them. When we made available an alternative behavioral option to sadism (here: prosocial behavior), boredom motivated sadism only in individuals who already had a relatively high basic sadistic tendency to begin with (i.e., individuals high in trait sadism). However, and remarkably, when we removed this "good" alternative, boredom indeed increased sadistic behavior, regardless of whether individuals started out with high or low basic sadistic tendencies. In sum, we present evidence that boredom motivates sadism across nine studies incorporating 15 samples from three different countries, from the lab, the classroom, and online. The effects persist across a wide range of correlational and experimental methodologies, from self-reported individual differences to experimental manipulations of boredom, and include not only questionnaire data but actual measures of sadistic behavior. Boredom is not merely a correlate of sadism; it causes sadistic behavior.

At this point, we also want to highlight that our independent variable (boredom) and our dependent variable (sadism) are conceptually clearly distinct. It is sometimes a problem in psychological research that independent variables are already partially confounded with, or 
"flavored" by, their associated dependent variables (e.g., neuroticism predicting depression, while depression is one facet of neuroticism in Big Five models; e.g., Jorm et al., 2000). This is decidedly not the case for the relationship between boredom and sadism—neither conceptually nor in terms of measurement; neither the experimental manipulation of boredom nor the self-report items of state or trait boredom bear any reference to interpersonal destructiveness. In fact, given that boredom and sadism are conceptually clearly distinct constructs, the fact that we see effect sizes above $r=.30$, as in some of the present studies, is remarkable (cf. Funder \& Ozer, 2019). These results have numerous implications for research on sadism and boredom, as well as for society. We discuss these implications in the following sections.

\section{Understanding the emergence of sadism}

In recent years, a large number of articles on sadism have been published. This research shows that sadism is a distinct motivational orientation which predicts a variety of destructive behavior such as online trolling, bullying, vandalism, and playing violent video games (Buckels et al., 2014; Greitemeyer, 2015; Greitemeyer et al., 2017, 2019; Johnson et al., 2019; Paulhus, 2014; Pfattheicher, Keller, \& Knezevic, 2019; van Geel et al., 2017). We contribute to this by pointing out several additional contexts where sadism may emerge, contexts so far overlooked in research on sadism: in the military, among parents during child care, and in private (sadistic) fantasies.

More importantly, despite the large body of work on sadism, little is known about when sadistic tendencies actually emerge. Research on this question is still in its infancy. As such, the present contribution addresses this remarkable gap. Specifically, we highlight four factors that contribute to the emergence of sadistic behavior. First, and most importantly, we provide evidence for one overlooked factor that motivates sadism: boredom. Second, we show that some individuals are more likely than others to be sadistic; trait sadism itself increases the likelihood that an individual will behave sadistically. Third, the results of Studies 7 to 9 point to the importance of behavioral alternatives. When no alternative behavioral option was available, our experimental 
boredom manipulation increased sadistic acts of destruction, even among individuals otherwise low in trait sadism. However, when given an alternative behavioral option, boredom only increased destructiveness among those already predisposed to sadism (i.e., those high in trait sadism).

We did not prominently highlight the fourth factor in our present work (due to our focus on boredom) but it is an important one: opportunity. Specifically, Study 8 reveals that giving individuals a longer opportunity to engage in sadism increased the likelihood that individuals use that opportunity to do so. This effect was particularly pronounced for individuals high in trait sadism. Reversely formulated, reducing the opportunity to engage in sadism reduced the likelihood that sadistic individuals in particular would engage in sadistic actions. This finding is consistent with basic social psychological theories highlighting the crucial role of motivation and opportunity in the execution of behavior (e.g., the MODE model by Fazio, 1990). As such, the present contribution reveals four important factors regarding when sadistic tendencies actually emerge: boredom; trait sadism; lack of behavioral alternatives; and, opportunity.

\section{Implications for research on boredom}

The present research also has important implications for our understanding of boredom. Previous work has focused largely on the intra-personal consequences of boredom, finding a wide array of negative (e.g., mood disorders, substance abuse; LePera, 2011, Weybright et al., 2015), neutral (e.g., doodling, Andrade, 2010), and positive outcomes (e.g., creativity, Harris, 2000; prosocial behavior, Tilburg and Igou, 2017). ${ }^{10}$ However, little is known about the potential interpersonal consequences of boredom, and next to nothing is known about its potential negative interpersonal consequences. This work is the first to show that boredom can cause harmful behaviors towards other individuals, namely in the form of sadism. In this way, the present contribution fills an important gap in the literature on boredom and draws a more nuanced picture

\footnotetext{
${ }^{10}$ See Supplementary Material on the OSF (https://osf.io/k2swy) for a discussion of our findings in relation to the results from Tilburg and Igou (2017).
} 
by considering not only the constructive but also the destructive potential that boredom holds. This is particularly relevant, given the recent proliferation of media calls by public intellectuals, from op-eds in the New York Times (Paul, 2019) to popular self-help books (Zomorodi, 2017), that urge us to experience more (rather than less) boredom, without perhaps fully realizing the full implications of doing so.

Boredom, like all emotions, can be experienced in many ways. It is often (but not always) accompanied by distorted perceptions of time, increased agitation or dysphoria, and altered patterns of arousal; indeed, past research has found state boredom to be associated with low arousal (Mercer \& Eastwood, 2010; Posner et al., 2005; Thackray et al., 1977; van Tilburg \& Igou, 2017), high arousal (Abramson \& Stinson, 1977; London \& Monello, 1980; London et al., 1972; Ohsuga, Shimono, \& Genno, 2001), and both high-and-low arousal (Chin et al., 2017; Eastwood et al., 2012; Fahlman et al., 2013; Goetz et al., 2006, 2014; Mercer-Lynn et al., 2014; Merrifield \& Danckert, 2014; Milyavskaya et al., 2019; Raffaelli et al., 2018). One way to disentangle these different forms of boredom is to look at their specific source, or causes, in accordance with modern constructivist views on emotion (Barret, 2006, 2012, 2017). Westgate and Wilson (2018) have identified two major independent sources of boredom: deficits in meaning and attention. In the present paper, we have concerned ourselves with prototypical instances of boredom — primarily mixed states caused by simultaneous deficits in both (Chin et al., 2017; van Tilburg \& Igou, 2012, 2017). We have argued that both sources of boredom can motivate sadism, in that sadistic behavior can serve to directly counter inattention and can be used indirectly (as a distraction) in coping with deficits in meaning. Because we were concerned with establishing the ecological validity of boredom's role in sadism, we were most interested in boredom as it most commonly occurs in everyday life. Our individual difference measures and boredom inductions thus reflect this approach by measuring and inducing prototypical mixed boredom states. 
In our experimental studies, therefore, it is highly likely that both sources of boredomattention and meaning deficits-were present. For instance, watching a video of a stone is both purposeless and under-stimulating, likely resulting in both meaning and attention deficits. Thus, while our results suggest that such prototypical boredom states increase sadistic behavior, we cannot disentangle the independent effects of the two sources of boredom. To do so would require boredom manipulations that induce deficits in meaning only (without simultaneously inducing deficits in attention) and vice versa. We note that this confounding of causes is typical in the literature on boredom, which has by and large induced boredom via mixed states. An important next step for research on boredom (not only for the understanding of sadism but for downstream consequences in many domains) is to experimentally manipulate different forms of boredom by disentangling their sources.

A natural question then is what are the specific processes through which boredom motivates sadism? We provide evidence that sadism stemming from prototypical boredom is driven by excitement seeking and seeking out novel experiences, but less so by seeking out meaningful activities (see Study 9). Thus, although our experimental manipulation induced prototypical boredom, which consists primarily of mixed states caused by simultaneous deficits in both attention and meaning (Chin et al., 2017; van Tilburg \& Igou, 2012, 2017), only the processes related to attention (excitement seeking and novelty seeking), but not processes related to lack of meaning, drove boredom-induced sadism. Does this mean that a need for meaning never plays a role in sadistic actions? This is indeed a relevant question for future research — by separately inducing boredom via meaning deficits (independent of attention deficits), researchers might test the destructive impact of boredom stemming only from a lack of meaning, but not lack of attention. In discussing the psychological process for the relation between boredom and sadism, we also want to acknowledge that we have only examined the impact of three possible mediators. In fact, there is good reason to believe that additional mechanisms, such as overall reward 
sensitivity (Milyavskaya et al., 2019) or impulsiveness (Moynihan et al., 2017), might also play a role in the link between boredom and sadism (see Supplementary Material for a discussion of impulsiveness; https://osf.io/k2swy).

\section{Applied implications}

In addition to its theoretical contributions to work more broadly on sadism and boredom, we would be remiss in not discussing the present work's potential applied implications. For instance, the present research highlights several important societal contexts where boredom might foster sadism. We document the relationship when it comes to sadistic behavior on the internet (i.e., trolling), in the military, during child care, and when it comes to sadistic fantasies. While the present research cannot directly establish a causal relationship in these contexts (which would indeed require a difficult undertaking), these results are promising, especially in light of the experimental evidence we report for boredom's role in directly causing sadistic behavior in more tightly controlled settings. Overall, these results suggest the potential for beneficial interventions to reduce boredom in important societal contexts; such interventions, if deployed as randomized controlled trials, could additionally be used to empirically test whether relieving boredom in these contexts causally reduces sadism.

Such interventions might be used to complement currently existing programs, for instance in schools. Interventions to reduce bullying already exist, such as those focusing on mindfulness interventions (Ramsey \& Jones, 2015) or on strengthening empathy (Garandeau et al., 2016). These programs focus on changing the individual. This, however, might be especially difficult in the context of (sadistic) bullying, given that sadistic individuals have chronic deficits in their empathic concern for the suffering of others (Sest \& March, 2017; Kirsch \& Becker, 2007). From this perspective, a more promising approach may be to change the situation individuals are in (rather than focusing on "fixing" the individual him/herself). 
The present results suggest two routes to doing so: first, by reducing the attention and meaning deficits that contribute to boredom directly, and second, by helping people make better choices when bored. For instance, one promising avenue suggested by Studies 7 to 9 is to make productive, prosocial alternatives more readily available. Just as people low in sadism were less likely to behave sadistically when offered the chance to increase participants' payment instead (Study 7), so too might it help children to proactively offer other exciting and stimulating alternatives to bullying (e.g., sports, playing video games). Similarly, in Study 8 we found that reducing opportunity to engage in sadism reduced overall sadistic acts of destructiveness; thus, another intervention may be to simply reduce the opportunities for individuals to engage in sadistic acts (e.g., by better monitoring individuals' behavior, limiting unstructured free time in unmonitored group settings, or establishing strict injunctive anti-bullying social norms). Of course, such ideas need to be tested in the "real world" to be declared effective-in schools, in the military, or even through initiatives aimed at reducing boredom in individuals' private lives. We argue that the present research represents grounds for giving such interventions a try.

\section{Limitations and outlook}

Finally, we want to acknowledge additional limitations of the present work and point to potential future research. Several of these limitations have been discussed previously (e.g., the correlational design used in studying applied contexts; the need to disentangle the effects of boredom due to deficits in meaning vs. deficits in attention). We want to add five methodological points. The first is that our experimental manipulation examined effects of boredom on a shortterm scale. Thus, we cannot draw inferences about the effects of constant and ongoing boredom. In the real world, boredom can be present for hours at a time (e.g., in schools; at work; while waiting for the departure of a flight; in between combat in the military). In this regard, an interesting question for future research is to examine the effects of boredom on destructive behavior across longer time scales and to determine the real-world conditions under which 
boredom actually leads to destructive behavior (as well as inhibitory conditions when boredom does not lead to destructive behavior).

Second, we want to emphasize that we used an online boredom induction, during which participants could engage in sadistic acts and destructive behavior while they were bored (rather than afterward). This differs from many other experimental studies that typically assess the dependent variable after the end of the boredom manipulation. In contrast to this post-hoc method, our approach does not confound the experience of boredom with the relief that comes from ending a boring experience. It is also better aligned theoretically with the rationale for why boredom, mechanistically, might lead to sadistic behaviors; after all, people typically engage in emotion regulation while experiencing emotions, not after those emotions have already been resolved. However, with our method, we cannot test the "hangover hypothesis," or the idea that the effects of boredom on sadism might persist even after an episode of boredom has ended. Nonetheless, we argue that using on-line boredom manipulations is a methodological improvement to past research, and one which better reflects the actual processes of boredom regulation both theoretically and in its actual real-world instantiations.

Third, we want to acknowledge that part of the present work is based on scales that we have modified (e.g., the sadism scale in the military context); these modified scales should be revalidated for factor structure and construct validity (see Flake et al., 2017). This is a weakness of this study. Despite these limitations, the consistency of evidence across all nine studies (many of which use well-validated scales in unmodified form) suggests that boredom does indeed motivate (or relate to) sadism.

Fourth, the present studies remain silent about the ultimate goal(s) of bored individuals when they engage in sadistic behavior. Per definition, sadistic behavior consists of an aggressive act while experiencing pleasure. However, because the aggressive act and the experienced pleasure are considerably correlated in all studies, we cannot disentangle the aggressive act from 
the experienced pleasure. Thus, the present work remains silent whether boredom increases experienced pleasure over and above the aggressive act.

Finally, we want to acknowledge that sadism is not a phenomenon that applies to everyone. In fact, the overall levels of sadism observed in the present studies were low; thus, some might argue that sadistic behavior is so infrequent as to not be worth investigating. However, sadistic behavior does occur, and as suggested in Studies 2 to 5, it occurs in important societal contexts with severe negative consequences for the harmed individuals. Given its severity, understanding sadistic behavior and the conditions that motivate it are important, despite its relative rarity.

In addition, certain moderators may explain why some of those high in sadism and boredom did not engage in sadistic behavior; social desirability might be one such candidate. By reducing social desirability concerns or providing individuals rationalization for sadistic behavior, future research might increase the base rate of sadistic behavior and find potentially stronger effects. We made a first step into this direction in Study 9 when individuals could punish an unfair other individual (i.e., a rationale for destruction). Moreover, while we find that effects of boredom consist even after controlling for another negative emotion (e.g., frustration), research on sadism would benefit from including other negative mood states in analysis (e.g., anger or pain). Chester and DeWall (2017; see also Chester et al., 2019), for instance, found increased sadistic tendencies (both in sadistic affect and behavior) after individuals were socially rejected or provoked, while anger plays a strong role in social rejection and provocation (e.g., Chow et al., 2008; Pfattheicher, Sassenrath, \& Keller, 2019). We hope that the present contribution stimulates future research that further advances our understanding of factors promoting sadistic tendencies.

Other outstanding questions for future research concern boredom's relationship with other forms of destructive behavior. We have taken the first steps to address this question by showing that boredom not only relates to sadistic behavior and tendencies, but also to additional antisocial 
tendencies like fantasizing about a bank robbery, to revenge fantasies, and to reactive aggression in the context of third-party punishment. However, it is likely that boredom is also related to other forms of destructive interpersonal behavior. In Study 1, for instance, we show that boredom is related to psychopathy (as proposed by Hare, 1991), though we did not further investigate behavioral indicators of psychopathy (e.g., bold criminal behavior) and their relation to boredom. In fact, although Hare (1991) proposed a relationship between boredom and psychopathy, there is a somewhat surprising gap of empirical studies on the role of boredom in psychopathy. Thus, a promising path for future research would be to investigate the causal role of boredom in the development of psychopathy, and to show which destructive and aggressive tendencies are related to boredom and which are not.

While sadistic aggression constitutes one form of aggressive behavior, aggression more broadly comes in a wide variety of forms, each characterized by very different causes and motives. For instance, instrumental aggression depends on whether aggressive acts accomplish a specific goal — some aggressive acts are done with the ultimate goal of harming another individual, whereas other aggressive acts are used as instrumental means to accomplish a different ultimate goal (e.g., robbing a pensioner with the ultimate goal of gaining money). Likewise, aggression ranges from overt aggression to more covert forms; there is aggression that relies on deep reflective thinking and planning (e.g., premeditated murder), and there is aggression that reflects more impulsive reactions (e.g., spontaneously punishing a person who has violated a social norm). Because we were drawing on a theoretical perspective that emphasizes lack of attention and lack of meaning as sources of boredom, we predicted that boredom would motivate the kinds of aggressive behavior that counter boredom stemming from these sources. Thus, we predicted that boredom should motivate sadistic aggression, and we report empirical evidence consistent with this prediction above. However, whether effects generalize to other forms of aggression is an intriguing question; we consider it both possible and probable that the effects of boredom on 
sadistic regression reflect a broader effect of boredom on aggression. Conversely, it is also possible that certain kinds of aggression are more likely when bored than others; for instance, we would predict that aggressive behavior that satisfies a need for stimulation or that can counter feelings of meaninglessness should be more readily fostered by feelings of boredom. Because aggression comes in such a wide variety of forms, investigating this question would require examining whether boredom motivates aggression across many different manifestations. While the focus of this paper is predominantly sadistic aggression, Study 9 constitutes an initial step in this direction, showing that boredom can motivate sadistic (proactive) aggression, but reactive aggression as well. We want to acknowledge, however, that we do not know whether the present findings are due to something unique about sadism as opposed to a broader association with aggression, which is manifested in certain cases as sadism. In other words, we cannot conclude from the present results whether the effects observed are due to a broader effect of boredom on aggression, manifested in the form of sadistic aggression, or to a unique relation between boredom and sadism. We hope the studies described will form a starting point for examining boredom and its relationship with different forms of aggression.

Finally, we want to emphasize that while the present research investigates a variety of situations in which boredom might motivate sadism, its effects are not necessarily limited to these contexts. It is likely that such effects generalize to other societally important contexts which have not yet been studied. For instance, one might wonder whether boredom on a military mission not only leads to harming one's fellow soldiers, as studied here, but also to harming members of enemy troops. Sadistic actions towards members of enemy troops are well documented (e.g., Bartone, 2005); it is relevant to ask to what extent boredom might be involved in such behaviors. Moreover, the idea that boredom causes sadism is also relevant for clinicians, for understanding why and when some clients might engage in intense sadistic behavior and for helping them modify 
this behavior. In essence, we argue that the present research forms a solid basis for work on boredom and sadism that can be applied across a broad variety of societal contexts.

\section{Conclusions}

In the present work, we have documented that sadistic tendencies can result from boredom. We provide correlational and experimental evidence that boredom is related to sadism across a wide array of societal contexts, and that this relationship is not merely associative but causal. In this regard, our work contributes to a better understanding regarding the determinants of sadism and the emerging destructive potential of boredom. As such, the current research opens new avenues of research for studying boredom and sadism, hopefully inspiring both basic research as well as work from an applied, societal perspective. 


\section{References}

Andrade, J. (2010). What does doodling do? Applied Cognitive Psychology, 24, 100-106.

Abbink, K., \& Sadrieh, A. (2009). The pleasure of being nasty. Economics Letters, 105, 306-308.

Abramson, E. E., \& Stinson, S. G. (1977). Boredom and eating in obese and non-obese individuals. Addictive Behaviors, 2, 181-185.

Anderson, A. E., \& Marcus, D. K. (2019). A bifactor model of meanness, coldheartedness, callousness, and sadism. Personality and Individual Differences, 137, 192-197.

Ashton, M. C., \& Lee, K. (2009). The HEXACO-60: A short measure of the major dimensions of personality. Journal of Personality Assessment, 91, 340-345.

Baird, B., Smallwood, J., Mrazek, M. D., Kam, J. W., Franklin, M. S., \& Schooler, J. W. (2012). Inspired by distraction: Mind wandering facilitates creative incubation. Psychological Science, 23, 1117-1122.

Barrett, L. F. (2006). Are emotions natural kinds? Perspectives on Psychological Science, 1, 2858.

Barrett, L. F. (2012). Emotions are real. Emotion, 12, 413-429.

Barrett, L. F. (2017). How emotions are made: The secret life of the brain. New York: Houghton Mifflin Harcourt.

Barbalet, J. M. (1999). Boredom and social meaning. British Journal of Sociology, 50, 631-646.

Baron, R. A., \& Richardson, D. R. (1994). Human aggression. Springer Science \& Business Media.

Bartone, P. T. (2005). The need for positive meaning in military operations: Reflections on Abu Ghraib. Military Psychology, 17, 315-324.

Bartone, P. T. (2006). Resilience under military operational stress: Can leaders influence hardiness? Military Psychology, 18, 131-148.

Baumeister, R. F., \& Campbell, W. K. (1999). The intrinsic appeal of evil: Sadism, sensational thrills, and threatened egotism. Personality and Social Psychology Review, 3, 210-221. 
Baumeister, R. F., \& Campbell, W. K. (1999). The intrinsic appeal of evil: sadism, sensational thrills, and threatened egotism. Personality and Social Psychology Review, 3, 210-221.

Baumeister, R. F., \& Landau, M. J. (2018). Finding the meaning of meaning: Emerging insights on four grand questions. Review of General Psychology, 22, 1-10.

Bench, S. W., \& Lench, H. C. (2019). Boredom as a seeking state: Boredom prompts the pursuit of novel (even negative) experiences. Emotion, 19, 242-254.

Bench, S. W., \& Lench, H. C. (2013). On the function of boredom. Behavioral Sciences, 3, 459472.

Bertl, B., Pietschnig, J., Tran, U. S., Stieger, S., \& Voracek, M. (2017). More or less than the sum of its parts? Mapping the Dark Triad of personality onto a single Dark Core. Personality and Individual Differences, 114, 140-144.

Borkenau, P. \& Ostendorf. F. (1993). NEO-Fünf-Faktoren Inventar nach Costa \& McCrae [NEOFive-Factor Questionnaire according to Costa \& McCrae]. Göttingen: Hogrefe.

Buckels, E. (2018). The psychology of everyday sadism. Doctoral dissertation, University of British Columbia, Vancouver, Canada.

Buckels, E. E., \& Paulhus, D. L. (2014). Comprehensive Assessment of Sadistic Tendencies (CAST). Unpublished instrument, University of British Columbia, Vancouver, Canada.

Buckels, E. E., Trapnell, P. D., \& Paulhus, D. L. (2014) Trolls just want to have fun. Personality and Individual Differences, 67, 97-102.

Buckels, E. E., Jones, D. N., \& Paulhus, D. L. (2013). Behavioral confirmation of everyday sadism. Psychological Science, 24, 2201-2209.

Buckels, E. E., Trapnell, P. D., Andjelovic, T., \& Paulhus, D. L. (2019). Internet trolling and everyday sadism: Parallel effects on pain perception and moral judgment. Journal of Personality, 87, 328-340. 
Chabrol, H., van Leeuwen, N., Rodgers, R., \& Séjourné, N. (2009). Contributions of psychopathic, narcissistic, Machiavellian, and sadistic personality traits to juvenile delinquency. Personality and Individual Differences, 47, 734-739.

Chapman, A. L., \& Dixon-Gordon, K. L. (2007). Emotional antecedents and consequences of deliberate self-harm and suicide attempts. Suicide and Life-Threatening Behavior, 37, 543552.

Chester, D.S. (2017). The role of positive affect in aggression. Current Directions in Psychological Science, 26, 366-370.

Chester, D.S. \& DeWall, C.N. (2017). Combating the sting of rejection with the pleasure of revenge: A new look at how emotion shapes aggression. Journal of Personality and Social Psychology, 112, 413-430.

Chester, D.S., DeWall, C.N., \& Enjaian, B. (2019). Sadism and aggressive behavior: Inflicting pain to feel pleasure. Personality and Social Psychology Bulletin, 45(8), 1252-1268.

Chin, A., Markey, A., Bhargava, S., Kassam, K. S., \& Loewenstein, G. (2017). Bored in the USA: Experience sampling and boredom in everyday life. Emotion, 17, 359-368.

Chow, R. M., Tiedens, L. Z., \& Govan, C. L. (2008). Excluded emotions: The role of anger in antisocial responses to ostracism. Journal of Experimental Social Psychology, 44, 896-903.

Cikara, M., Bruneau, E. G., Van Bavel, J. J., \& Saxe, R. (2014). Their pain gives us pleasure: How intergroup dynamics shape empathic failures and counter-empathic responses. Journal of Experimental Social Psychology, 55, 110-125.

Cohen, J. (1992). A power primer. Psychological Bulletin, 112, 155-159.

Coughlan, G., Igou, E. R., van Tilburg, W. A., Kinsella, E. L., \& Ritchie, T. D. (2019). On boredom and perceptions of heroes: A meaning-regulation approach to heroism. Journal of Humanistic Psychology, 59, 455-473.

Csikszentmihalyi, M. (2000). Beyond boredom and anxiety: Experiencing flow in work and play. San Francisco: Jossey-Bass. 
Csikszentmihalyi, M., \& Larson, R. (1978). Intrinsic rewards in school crime. Crime \& Delinquency, 24, 322-335.

Culp, N. A. (2006). The relations of two facets of boredom proneness with the major dimensions of personality. Personality and Individual Differences, 41, 999-1007.

Dahlen, E. R., Martin, R. C., Ragan, K., \& Kuhlman, M. M. (2004). Boredom proneness in anger and aggression: Effects of impulsiveness and sensation seeking. Personality and Individual Differences, 37, 1615-1627.

Danckert, J., \& Merrifield, C. (2018). Boredom, sustained attention and the default mode network. Experimental Brain Research, 236, 2507-2518.

Davidson, A. R., \& Jaccard, J. J. (1979). Variables that moderate the attitude-behavior relation: Results of a longitudinal survey. Journal of Personality and Social Psychology, 37, 13641376.

Demaray, M. K., Summers, K. H., Jenkins, L. N., \& Becker, L. D. (2014). Bullying Participant Behaviors Questionnaire (BPBQ): Establishing a reliable and valid measure. Journal of School Violence, 15, 1-31.

De Quervain, D. J., Fischbacher, U., Treyer, V., \& Schellhammer, M. (2004). The neural basis of altruistic punishment. Science, 305, 1254.

Dietz, P. E., Hazelwood, R. R., \& Warren, J. (1990). The sexually sadistic criminal and his offenses. Journal of the American Academy of Psychiatry and the Law Online, 18, 163178.

Eastwood, J. D., Frischen, A., Fenske, M. J., \& Smilek, D. (2012). The unengaged mind: Defining boredom in terms of attention. Perspectives on Psychological Science, 7, 482-495.

Elpidorou, A. (in press). Is boredom one or many? A functional solution to the problem of heterogeneity. Mind \& Language.

Eriksson, K., Strimling, P., Andersson, P. A., \& Lindholm, T. (2017). Costly punishment in the ultimatum game evokes moral concern, in particular when framed as payoff reduction. Journal of Experimental Social Psychology, 69, 59-64. 
Fahlman, S. A., Mercer-Lynn, K. B., Flora, D. B., \& Eastwood, J. D. (2013). Development and validation of the multidimensional state boredom scale. Assessment, 20, 68-85.

Farmer, R., \& Sundberg, N. D. (1986). Boredom proneness - the development and correlates of a new scale. Journal of Personality Assessment, 50, 4-17.

Faul, F., Erdfelder, E., Buchner, A., \& Lang, A. G. (2009). Statistical power analyses using G* Power 3.1: Tests for correlation and regression analyses. Behavior Research Methods, 41, 1149-1160.

Fazio, R. H. (1990). Multiple processes by which attitudes guide behavior: The MODE model as an integrative framework. In Advances in experimental social psychology (Vol. 23, pp. 75109). San Diego: Academic Press.

Ferguson, F., \& McLean, S. (2019, February 11). Teen pointed gun at passing cars from M50 bridge 'was bored and messing.' Echo. Retrieved from: http://www.echo.ie/tallaght/article/teenpointed-gun-at-passing-cars-from-m50-bridge-was-bored-and-messing

Fehr, E., \& Fischbacher, U. (2004). Third-party punishment and social norms. Evolution and Human Behavior, 25, 63-87.

Flake, J. K., Pek, J., \& Hehman, E. (2017). Construct validation in social and personality research: Current practice and recommendations. Social Psychological and Personality Science, 8, 370-378.

Fromm, E. (1972). Fromm's theory of aggression. The New York Times Magazine, New York. Derived from: https://nyti.ms/2Gcd2Ve

Fromm, E. (1973). The anatomy of human destructiveness. New York, NY: Holt McDougal.

Funder, D. C., \& Ozer, D. J. (2019). Evaluating effect size in psychological research: Sense and nonsense. Advances in Methods and Practices in Psychological Science, 2, 156-168.

Gana, K., Broc, G., \& Bailly, N. (2019). Does the Boredom Proneness Scale capture traitness of boredom? Results from a six-year longitudinal trait-state-occasion model. Personality and Individual Differences, 139, 247-253. 
Garandeau, C. F., Vartio, A., Poskiparta, E., \& Salmivalli, C. (2016). School bullies' intention to change behavior following teacher interventions: Effects of empathy arousal, condemning of bullying, and blaming of the perpetrator. Prevention Science, 17, 1034-1043.

Goetz, T., Frenzel, A. C., Hall, N. C., Nett, U. E., Pekrun, R., \& Lipnevich, A. A. (2014). Types of boredom: An experience sampling approach. Motivation and Emotion, 38, 401-419.

Goetz, T., Frenzel, A. C., Pekrun, R., \& Hall, N. C. (2006). The domain specificity of academic emotional experiences. The Journal of Experimental Education, 75, 5-29.

Greitemeyer, T. (2015). Everyday sadism predicts violent video game preferences. Personality and Individual Differences, 75, 19-23.

Greitemeyer, T., \& Sagioglou, C. (2017). The longitudinal relationship between everyday sadism and the amount of violent video game play. Personality and Individual Differences, 104, 238-242.

Greitemeyer, T., Weiß, N., \& Heuberger, T. (2019). Are everyday sadists specifically attracted to violent video games and do they emotionally benefit from playing those games? Aggressive Behavior, 45, 206-213.

Hare, R. D. (1991). The Hare psychopathy checklist-revised (PCL-R). Toronto, Ontario: MultiHealth Systems.

Havermans, R. C., Vancleef, L., Kalamatianos, A., \& Nederkoorn, C. (2015). Eating and inflicting pain out of boredom. Appetite, 85, 52-57.

Harris, M. B. (2000). Correlates and characteristics of boredom proneness and boredom. Journal of Applied Social Psychology, 30, 576-598.

Hayes, A. F. (2018). Introduction to mediation, moderation, and conditional process analysis: A regression-based approach (2nd ed.). New York, NY: Guilford Press.

Heidelberg Institute for International Conflict Research (HIIK). (2019). Conflict Barometer 2018. Heidelberg: Campus Bergheim.

Hernandez, S. M. (2015). A better understanding of bullying and hazing in the military. Military Review, 223, 415-439. 
Isacescu, J., Struk, A. A., \& Danckert, J. (2017). Cognitive and affective predictors of boredom proneness. Cognition and Emotion, 31, 1741-1748.

John, O. P., Naumann, L. P., \& Soto, C. J. (2008). Paradigm shift to the integrative Big Five trait taxonomy: History, measurement, and conceptual issues. In O. P. John, R. W. Robins, \& L. A. Pervin (Eds.), Handbook of personality: Theory and research (pp. 114-158). New York, NY: Guilford Press.

Johnson, L. K., Plouffe, R. A., \& Saklofske, D. H. (2019). Subclinical sadism and the Dark Triad. Journal of Individual Differences, 140, 57-60.

Joireman, J., Anderson, J., \& Strathman, A. (2003). The aggression paradox: Understanding links among aggression, sensation seeking, and the consideration of future consequences. Journal of Personality and Social Psychology, 84, 1287-1302.

Jones, D. N., \& Paulhus, D. L. (2014). Introducing the short dark triad (SD3) a brief measure of dark personality traits. Assessment, 21, 28-41.

Jorm, A. F., Christensen, H., Henderson, A. S., Jacomb, P. A., Korten, A. E., \& Rodgers, B. (2000). Predicting anxiety and depression from personality: Is there a synergistic effect of neuroticism and extraversion? Journal of Abnormal Psychology, 109, 145-149.

Kierkegaard, S. (2009). Enten-eller [Either-or]. København: Gyldendal.

Kirsch, L. G., \& Becker, J. V. (2007). Emotional deficits in psychopathy and sexual sadism: Implications for violent and sadistic behavior. Clinical Psychology Review, 27, 904-922.

Lancaster, S. L., \& Erbes, C. R. (2017). Importance of moral appraisals in military veterans. Traumatology, 23, 317-322.

Lee, C. M., Neighbors, C., \& Woods, B. A. (2007). Marijuana motives: Young adults' reasons for using marijuana. Addictive Behaviors, 32, 1384-1394.

LePera, N. (2011). Relationships between boredom proneness, mindfulness, anxiety, depression, and substance use. The New School Psychology Bulletin, 8, 15-25. 
Lobbestael, J., van Teffelen, M., \& Baumeister, R. F. (in press). Psychopathy subfactors distinctively predispose to dispositional and state-level of sadistic pleasure. Journal of Behavior Therapy and Experimental Psychiatry.

London, H., \& Monello, L. (1974). Cognitive manipulation of boredom. In H. London \& R. Nisbett (Eds.), Thought and feeling (pp. 44-59). Chicago, IL: Aldine.

London, H., Schubert, D. S. P., \& Washburn, D. (1972). Increase of autonomic arousal by boredom. Journal of Abnormal Psychology, 80, 29-36.

Lynam, D. R., Hoyle, R. H., \& Newman, J. P. (2006). The perils of partialling: Cautionary tales from aggression and psychopathy. Assessment, 13, 328-341.

Lynam, D. R., \& Miller, J. D. (2019). The basic trait of Antagonism: An unfortunately underappreciated construct. Journal of Research in Personality, 81, 118-126.

Mackinnon, A., Jorm, A., Christensen, H., \& Korten, A. E. (1999). A short form of the Positive and Negative Affect Schedule: Evaluation of factorial validity and invariance across demographic variables in a community sample. Personality and Individual Differences, 27, 405-416.

March, E. (2019). Psychopathy, sadism, empathy, and the motivation to cause harm: New evidence confirms malevolent nature of the Internet Troll. Personality and Individual Differences, 141, 133-137.

Martens, A., Kosloff, S., Greenberg, J., Landau, M. J., \& Schmader, T. (2007). Killing begets killing: Evidence from a bug-killing paradigm that initial killing fuels subsequent killing. Personality and Social Psychology Bulletin, 33, 1251-1264.

Međedović, J. (2017). Aberrations in emotional processing of violence-dependent stimuli are the core features of sadism. Motivation and Emotion, 41, 273-283.

Mercer, K. B., \& Eastwood, J. D. (2010). Is boredom associated with problem gambling behaviour? It depends on what you mean by 'boredom'. International Gambling Studies, $10,91-104$.

Mercer-Lynn, K. B., Bar, R. J., \& Eastwood, J. D. (2014). Causes of boredom: The person, the situation, or both? Personality and Individual Differences, 56, 122-126. 
Merrifield, C., \& Danckert, J. (2014). Characterizing the psychophysiological signature of boredom. Experimental Brain Research, 232, 481-491.

Miller, J. D., Vize, C., Crowe, M. L., \& Lynam, D. R. (2019). A critical appraisal of the DarkTriad literature and suggestions for moving forward. Current Directions in Psychological Science, 28, 353-360.

Milyavskaya, M., Inzlicht, M., Johnson, T., \& Larson, M. J. (2019). Reward sensitivity following boredom and cognitive effort: A high-powered neurophysiological investigation. Neuropsychologia, 123, 159-168.

Moor, L., \& Anderson, J. R. (2019). A systematic literature review of the relationship between dark personality traits and antisocial online behaviours. Personality and Individual Differences, 144, 40-55.

Moshagen, M., Hilbig, B. E., \& Zettler, I. (2018). The dark core of personality. Psychological Review, 125, 656-688.

Moynihan, A. B., Igou, E. R., \& van Tilburg, W. A. (2017). Boredom increases impulsiveness. Social Psychology, 48, 293-309.

Muris, P., Merckelbach, H., Otgaar, H., \& Meijer, E. (2017). The malevolent side of human nature: A meta-analysis and critical review of the literature on the dark triad (narcissism, Machiavellianism, and psychopathy). Perspectives on Psychological Science, 12, 183-204.

Nederkoorn, C., Vancleef, L., Wilkenhöner, A., Claes, L., \& Havermans, R. C. (2016). Selfinflicted pain out of boredom. Psychiatry Research, 237, 127-132.

Nelissen, R. M., \& Zeelenberg, M. (2009). Moral emotions as determinants of third-party punishment: Anger, guilt and the functions of altruistic sanctions. Judgment and Decision Making, 4(7), 543.

Ohsuga, M., Shimono, F., \& Genno, H. (2001). Assessment of phasic work stress using autonomic indices. International Journal of Psychophysiology, 40, 211-220.

Olweus, D., \& Limber, S. P. (2018). Some problems with cyberbullying research. Current Opinion in Psychology, 19, 139-143. 
O’Meara, A., Davies, J., \& Hammond, S. (2011). The psychometric properties and utility of the Short Sadistic Impulse Scale (SSIS). Psychological Assessment, 23, 523-531.

Paananen, A., \& Reichl, A. J. (2019). Gendertrolls just want to have fun, too. Personality and Individual Differences, 141, 152-156.

Paul, P. (2019, February 2). Let children get bored again. The New York Times. Retrieved from https://www.nytimes.com/2019/02/02/opinion/sunday/children-bored.html

Paulhus, D. L. (2014). Toward a taxonomy of dark personalities. Current Directions in Psychological Science, 23, 421-426.

Paulhus D. L., \& Jones, D. N (2015). Measures of Dark Personalities. In G. J. Boyle, D. H. Saklofske, \& G. Matthews (Eds.), Measures of Personality and Social Psychological Constructs (pp. 562-594). San Diego, US: Academic Press.

Paulhus, D. L., \& Williams, K. M. (2002). The dark triad of personality: Narcissism, Machiavellianism, and psychopathy. Journal of Research in Personality, 36, 556-563.

Pekrun, R., Goetz, T., Daniels, L. M., Stupnisky, R. H., \& Perry, R. P. (2010). Boredom in achievement settings: Exploring control-value antecedents and performance outcomes of a neglected emotion. Journal of Educational Psychology, 102, 531.

Pfattheicher, S., Keller, J., \& Knezevic, G. (2017). Sadism, the intuitive system, and antisocial punishment in the public goods game. Personality and Social Psychology Bulletin, 43, 337-346.

Pfattheicher, S., Sassenrath, C., \& Keller, J. (2019). Compassion magnifies third-party punishment. Journal of Personality and Social Psychology, 117, 124-141.

Pfattheicher, S., Keller, J., \& Knezevic, G. (2019). Destroying things for pleasure: On the relation of sadism and vandalism. Personality and Individual Differences, 140, 52-56.

Pfattheicher, S., \& Schindler, S. (2015). Understanding the dark side of costly punishment: The impact of individual differences in everyday sadism and existential threat. European Journal of Personality, 29, 498-505. 
Pfattheicher, S., Schindler, S., \& Nockur, L. (2019). On the impact of Honesty-Humility and a cue of being watched on cheating behavior. Journal of Economic Psychology, 71, 159-174.

Posner, J., Russell, J. A., \& Peterson, B. S. (2005). The circumplex model of affect: An integrative approach to affective neuroscience, cognitive development, and psychopathology. Development and Psychopathology, 17, 715-734.

Raab, J. (2012, September 27). It's time to talk about what troops leave unsaid. The New York Times. Retrieved from https://atwar.blogs.nytimes.com/2012/09/27/its-time-to-talk-aboutwhat-troops-leave-unsaid/?register=email\&auth=register-email

Raffaelli, Q., Mills, C. \& Christoff, K. (2018). The knowns and unkowns of boredom: A review of the literature. Experimental Brain Research, 236, 2451-2462.

Ramsey, A. T., \& Jones, E. E. (2015). Minding the interpersonal gap: Mindfulness-based interventions in the prevention of ostracism. Consciousness and Cognition, 31, 24-34.

Russell, T. D., \& King, A. R. (2016). Anxious, hostile, and sadistic: Maternal attachment and everyday sadism predict hostile masculine beliefs and male sexual violence. Personality and Individual Differences, 99, 340-345.

Seli, P., Kane, M. J., Smallwood, J. S., Schacter, D. L., Maillet, D., Schooler, J. W., \& Smilek, D. (2018). Mind-wandering as a natural kind: A family-resemblance view. Trends in Cognitive Sciences, 22, 479-490.

Sest, N., \& March, E. (2017). Constructing the cyber-troll: Psychopathy, sadism, and empathy. Personality and Individual Differences, 119, 69-72.

Sleep, C. E., Lynam, D. R., Hyatt, C. S., \& Miller, J. D. (2017). Perils of partialing redux: The case of the Dark Triad. Journal of Abnormal Psychology, 126, 939-950.

Shachaf, P., \& Hara, N. (2010). Beyond vandalism: Wikipedia trolls. Journal of Information Science, 36, 357-370.

Stoltenborgh, M., Bakermans-Kranenburg, M. J., Alink, L. R., \& van IJzendoorn, M. H. (2015). The prevalence of child maltreatment across the globe: Review of a series of meta-analyses. Child Abuse Review, 24, 37-50. 
Struk, A. A., Carriere, J. S., Cheyne, J. A., \& Danckert, J. (2017). A short Boredom Proneness Scale: Development and psychometric properties. Assessment, 24, 346-359.

Thackray, R. I., Bailey, J. P., \& Touchstone, R. M. (1977). Physiological, subjective, and performance correlates of reported boredom and monotony while performing a simulated radar control task. In Vigilance (pp. 203-215). Springer, Boston, MA.

Troutwine, R., \& O'neal, E. C. (1981). Volition, performance of a boring task and time estimation. Perceptual and Motor Skills, 52, 865-866.

van Geel, M., Goemans, A., Toprak, F., \& Vedder, P. (2017). Which personality traits are related to traditional bullying and cyberbullying? A study with the Big Five, Dark Triad and sadism. Personality and Individual Differences, 106, 231-235.

van Tilburg, W. A., \& Igou, E. R. (2011). On boredom and social identity: A pragmatic meaningregulation approach. Personality and Social Psychology Bulletin, 37, 1679-1691.

van Tilburg, W. A., \& Igou, E. R. (2012). On boredom: Lack of challenge and meaning as distinct boredom experiences. Motivation and Emotion, 36, 181-194.

van Tilburg, W. A., \& Igou, E. R. (2013). On the meaningfulness of behavior: An expectancy x value approach. Motivation and Emotion, 37, 373-388.

van Tilburg, W. A., \& Igou, E. R. (2016). Going to political extremes in response to boredom. European Journal of Social Psychology, 46, 687-699.

van Tilburg, W. A., \& Igou, E. R. (2017). Boredom begs to differ: Differentiation from other negative emotions. Emotion, 17, 309-322,

van Tilburg, W. A., \& Igou, E. R. (2017). Can boredom help? Increased prosocial intentions in response to boredom. Self and Identity, 16, 82-96.

Van Tilburg, W. A., Igou, E. R., \& Sedikides, C. (2013). In search of meaningfulness: Nostalgia as an antidote to boredom. Emotion, 13, 450-461.

Weybright, E. H., Caldwell, L. L., Ram, N., Smith, E. A., \& Wegner, L. (2015). Boredom prone or nothing to do? Distinguishing between state and trait leisure boredom and its association with substance use in South African adolescents. Leisure Sciences, 37, 311-331. 
Westgate, E. C. (2020). Why boredom is interesting. Current Directions in Psychological Science, $29,33-40$.

Westgate, E. C., \& Wilson, T. D. (2018). Boring thoughts and bored minds: The MAC model of boredom and cognitive engagement. Psychological Review, 125, 689-713.

Wink, P., \& Donahue, K. (1997). The relation between two types of narcissism and boredom. Journal of Research in Personality, 31, 136-140.

Wilson, T. D., Reinhard, D. A., Westgate, E. C., Gilbert, D. T., Ellerbeck, N., Hahn, C., ... \& Shaked, A. (2014). Just think: The challenges of the disengaged mind. Science, 345, 75-77.

Wither, J. K. (2006). Battling bullying in the British army 1987-2004. In F. Daucé \& E. SiecaKozlowski (Eds.), Dedovshchina in the post-Soviet military: Hazing of Russian army conscripts in a comparative perspective (pp. 221-236). Stuttgart: Ibidem-Verlag.

Zhang, L., \& Ortmann, A. (2013). On the interpretation of giving, taking, and destruction in dictator games and joy-of-destruction games. UNSW Australian School of Business Research Paper.

Zhou, H., \& Fishbach, A. (2016). The pitfall of experimenting on the web: How unattended selective attrition leads to surprising (yet false) research conclusions. Journal of Personality and Social Psychology, 111, 493-504.

Zomorodi, M. (2017). Bored and brilliant: How spacing out can unlock your most productive and creative self. St. Martin's Press.

Zuckerman, M. (1971). Dimensions of sensation seeking. Journal of Consulting and Clinical Psychology, 36, 45-52.

Acknowledgment: We thank Isabel Abbt for her help with data collection of Study 5, and Sarah Kammermeier for her help with data collection of Study 6. The first author is indebted to the Baden-Württemberg Stiftung for the financial support of parts of this research project by the Eliteprogramme for Postdocs. Data and material of all studies are available on the Open Science Framework (see https://osf.io/k2swy). 